\title{
Current therapeutic approaches in the management of hemophilia-a consensus view by the Romanian Society of Hematology
}

\author{
Ionut Hotea ${ }^{1,2,3}$, Melen Brinza ${ }^{4,5}$, Cristina Blag ${ }^{6,7}$, Alina-Andreea Zimta ${ }^{3}$, Noemi Dirzu ${ }^{3}$, Corina Burzo ${ }^{2}$, \\ Ioana Rus ${ }^{1}$, Dragos Apostu ${ }^{8,9}$, Horea Benea ${ }^{8,9}$, Mirela Marian ${ }^{2}$, Alexandru Mester ${ }^{10}$, Sergiu Pasca ${ }^{1}$, \\ Sabina Iluta ${ }^{1}$, Patric Teodorescu ${ }^{1}$, Ciprian Jitaru ${ }^{1}$, Mihnea Zdrenghea ${ }^{1,2}$, Anca Bojan ${ }^{1,2}$, \\ Tunde Torok-Vistai ${ }^{1,2}$, Radu Niculescu $^{4}$, Cristina Tarniceriu ${ }^{11,12}$, Delia Dima ${ }^{2}$, Cristina Truica ${ }^{13}$, \\ Margit Serban $^{14,15}$, Ciprian Tomuleasa ${ }^{1,2,3}$, Daniel Coriu ${ }^{4,5}$
}

${ }^{1}$ Department of Hematology, Iuliu Hatieganu University of Medicine and Pharmacy, Cluj Napoca, Romania; ${ }^{2}$ Department of Hematology, Ion Chiricuta Clinical Cancer Center, Cluj Napoca, Romania; ${ }^{3}$ Medfuture Research Center for Advanced Medicine, Iuliu Hatieganu University of Medicine and Pharmacy, Cluj Napoca, Romania; ${ }^{4}$ Department of Hematology, Fundeni Clinical Institute, Bucharest, Romania; ${ }^{5}$ Department of Hematology, Carol Davila University of Medicine and Pharmacy, Bucharest, Romania; ${ }^{6}$ Department of Pediatrics, Iuliu Hatieganu University of Medicine and Pharmacy, Cluj Napoca, Romania; ${ }^{7}$ Department of Hematology, Emergency Clinical Children's Hospital, Cluj Napoca, Romania; ${ }^{8}$ Department of Orthopedics, Iuliu Hatieganu University of Medicine and Pharmacy, Cluj Napoca, Romania; ${ }^{9}$ Department of Orthopedics, Emergency Clinical County Hospital, Cluj Napoca, Romania; ${ }^{10}$ Department of Oral Health, Iuliu Hatieganu University of Medicine and Pharmacy, Cluj Napoca, Romania; ${ }^{11}$ Department of Anatomy, Grigore T. Popa University of Medicine and Pharmacy, Iasi, Romania; ${ }^{12}$ Department of Hematology, St. Spiridon County Clinical Emergency Hospital, Iasi, Romania; ${ }^{13}$ Department of Hematology, Constantin Opris Emergency Hospital, Baia Mare, Romania; ${ }^{14}$ Department of Hematology, Victor Babes University of Medicine and Pharmacy, Timisoara, Romania; ${ }^{15}$ European Haemophilia Treatment Center, Timisoara, Romania

Contributions: (I) Conception and design: I Hotea, M Zdrenghea, C Blag; (II) Administrative support: R Niculescu, C Tarniceriu, D Dima, C Truica, M Serban, C Tomuleasa, D Coriu; (III) Provision of study materials or patients: AA Zimta, N Dirzu, C Burzo, I Rus, D Apostu, H Benea, M Marian, A Mester, S Pasca, S Iluta, P Teodorescu, C Jitaru, M Zdrenghea, A Bojan, T Torok-Vistai; (IV) Collection and assembly of data: AA Zimta, N Dirzu, C Burzo, I Rus, D Apostu, H Benea, M Marian, A Mester, S Pasca, S Iluta, P Teodorescu, C Jitaru, M Zdrenghea, A Bojan, T Torok-Vistai; (V) Data analysis and interpretation: S Pasca, C Tomuleasa; (VI) Manuscript writing: All authors; (VII) Final approval of manuscript: All authors.

Correspondence to: Ciprian Tomuleasa, MD. Iuliu Hatieganu University of Medicine and Pharmacy, 73 Rd-21 street of December Boulevard, 400124 , Cluj Napoca, Romania. Email: ciprian.tomuleasa@umfcluj.ro; cipriantomuleasa@gmail.com.

\begin{abstract}
Hemophilia A (HA) and hemophilia B (HB) are rare disorders, being caused by the total lack or under-expression of two factors from the coagulation cascade coded by genes of the $\mathrm{X}$ chromosome. Thus, in hemophilic patients, the blood does not clot properly. This results in spontaneous bleeding episodes after an injury or surgical intervention. A patient-centered regimen is considered optimal. Age, pharmacokinetics, bleeding phenotype, joint status, adherence, physical activity, personal goals are all factors that should be considered when individualizing therapy. In the past 10 years, many innovations in the diagnostic and treatment options were presented as being either approved or in development, thus helping clinicians to improve the standard-of-care for patients with hemophilia. Recombinant factors still remain the standard of care in hemophilia, however they pose a challenge to treatment adherence because they have short halflife, which where the extended half-life (EHL) factors come with the solution, increasing the half-life to 96 hours. Gene therapies have a promising future with proven beneficial effects in clinical trials. We present and critically analyze in the current manuscript the pros and cons of all the major discoveries in the diagnosis and treatment of HA and HB, as well as identify key areas of hemophilia research where improvements are needed.
\end{abstract}

Keywords: Hemophilia; diagnosis and management; consensus view; Romanian Society of Hematology 
Submitted Feb 15, 2021. Accepted for publication May 17, 2021.

doi: $10.21037 / \mathrm{atm}-21-747$

View this article at: https://dx.doi.org/10.21037/atm-21-747

\section{Introduction}

During an injury or a surgical intervention, the prevention of massive blood loss requires immediate actions to be taken, while maintaining blood fluidity and restricting the clotting process only to the site of vascular injury (prevention of thrombosis). Therefore, a complex and dynamic therapeutic approach, which includes an equilibrium of procoagulants, anticoagulants, and fibrinolytic drugs enable hemostasis without causing thrombosis (1). These drugs include serine protease zymogens and protein cofactors activated in a certain order and initiate the coagulation cascade at the site of vascular damage (2-4).

Hemophilia A (HA) and hemophilia B (HB) are two rare genetic disorders (1), caused by the total lack or the under-expression of two factors from the coagulation cascade coded by genes of the $\mathrm{X}$ chromosome (2). Thus, in hemophilic patients the blood does not clot properly. This results in spontaneous bleeding episodes bleeding following an injury or surgical intervention, in comparison with healthy individuals. Generally speaking, there are two main types of hemophilia: HA, which is due to low levels of factor VIII (FVIII), and HB, which is due to low levels of factor IX (FIX) (3). Hemophilia (whether HA or HB) is classified into 3 degrees of severity depending on the plasma level of the respective factor. The categories are as follows: severe (level of factor less than $1 \mathrm{IU} / \mathrm{dL},<1 \%$ of normal), moderate (level of factor $1-5 \mathrm{IU} / \mathrm{dL}, 1-5 \%$ of normal) and mild (level of factor $5-40 \mathrm{IU} / \mathrm{dL}, 5-40 \%$ of normal) $(3,4)$. The coagulation cascade and the roles of FVIII and FIX are illustrated in Figure 1.

The lack of any of these two factors, FVIII or FIX, leads to spontaneous bleedings especially in the joints, that can lead to hemophilic arthropathy, which reduces the mobility of the joints thus significantly impacting the quality of life of hemophilic patients (5-7). Patients that are treated with primary prevention without signs of active bleedings, are less likely to develop hemophilic arthropathy. On demand treatment is where factor concentrate is infused when a bleed occurs. Prophylaxis represents the infusion of clotting factor concentrates to prevent bleeding. On the other hand, patients who are treated with "on demand" factor develop hemophilic arthropathy more often $(7,8)$. Other, less frequent musculoskeletal complications in hemophilia are involuntary muscle contractions, higher susceptibility to fractures. and formation of pseudotumors in the soft tissue and bones (7). Patients who develop allogenic inhibitors are at an even higher risk category and their treatment poses additional challenges (9-11).

In the past 10 years, we have seen many innovations in the diagnostic and treatment options of hemophilia that help, approved or in development, thus helping clinicians to continuously improve the standard of care (12). In the current review of literature, we present and critically analyze the pros and cons of all the major discoveries in the diagnosis and treatment of $\mathrm{HA}$ and $\mathrm{HB}$, as well as identify key areas of hemophilia research where improvements are needed.

\section{Diagnostic tools}

\section{Classical confirmation and classification tests, prognosis assessment}

To improve the quality of life for hemophilic patients, an efficient diagnostic tool is the first important aspect.

Prothrombin time (PT) evaluates the extrinsic and common pathways of coagulation. It measures the activity of factors I, II, V, VII, and X. To the platelet poor plasma (PPP), calcium, and thromboplastin are added. Afterwards the time to complete clot formation is measured (13). In hemophilia, PT was normal levels (14). Thrombin time (TT) represents the time (seconds) in which the patient's plasma clots after adding thrombin and calcium ions. In hemophilia, TT is also not modified (15).

Activated partial thromboplastin time (APTT) is a functional test that assesses both the intrinsic and the common pathways of the coagulation cascade (16). In moderate and severe hemophilia, APTT is markedly prolonged. Still, in mild cases, APTT can be within normal limits. This test is also more sensitive to detect lack of FVIII, than lack of FIX, which is why it is important to also associate this test with a specific factor evaluation analysis (15). It is worth mentioning that the APTT has been shown to have statistically different results, depending on the regents used (17). 


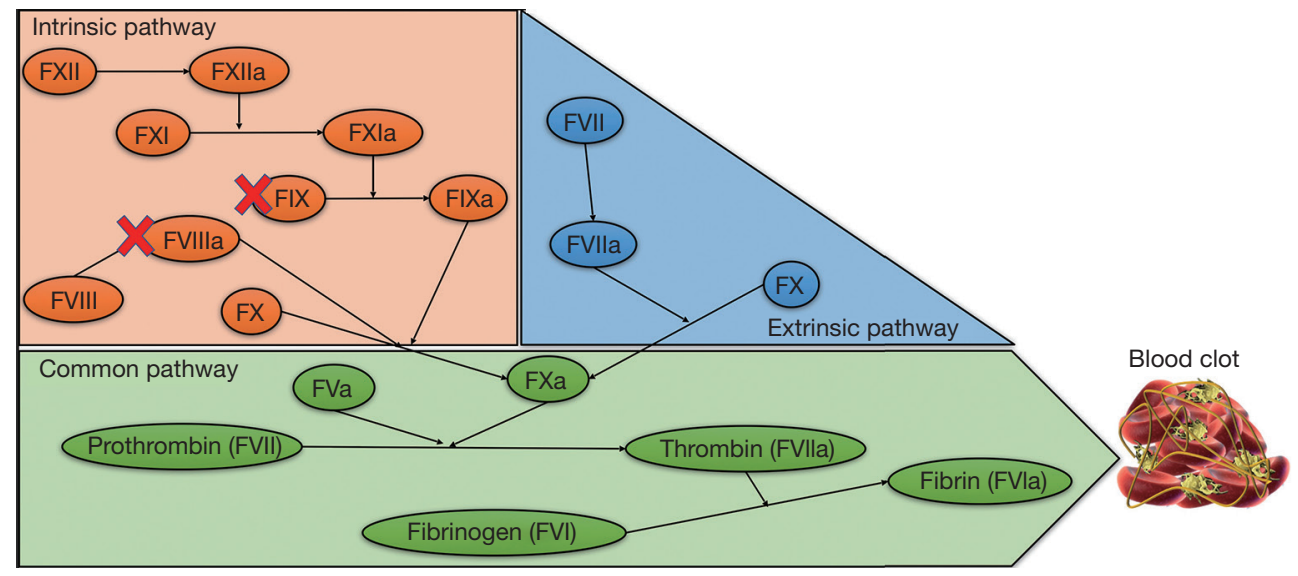

Figure 1 This cascade is initiated by the exposure of the extravascular protein Tissue Factor (TF) to blood, allowing the formation of the TF-factor VIIa (FVIIa) complex. This complex is able to activate small amounts of FIXa and FXa before it is rapidly inhibited by TF pathway inhibitor (TFPI). FXa promotes the generation of thrombin. Although no sufficient amounts of thrombin are produced to allow fibrin formation, thrombin amplifies its own production by inducing a positive feedback loop via activation of FXI and the protein cofactors FV and FVIII. This feedback activation is crucial for the formation of the FIXa/FVIIIa complex (also known as the tenase complex), which is needed to generate adequate amounts of FXa and thrombin to permit fibrin formation. Now, it is known that the contact pathway (or intrinsic pathway) is not needed for normal hemostasis in vivo.

A mixing study is performed to determine whenever the elongation of APTT occurs in association with normal PT, TT, and platelet count. Plasma from the patient is mixed 1:1 with a reference control plasma. The initial abnormal test then is rechecked. If the APTT of the mix is completely corrected, the patient has a deficiency of clotting factor (18). If the mix does not correct the APTT values or the correction is incomplete, the patient has developed clotting factor inhibitors (19). Mixing studies can also be done with the PT to investigate deficiencies of factor VII, X, and V.

Chromogenic assay (a two-stage assay) is using the activation of FX. In the first stage, FVII and FIX are added to the patient's plasma which activates FX. The activated FX cleaves a chromogenic substrate generating color whose intensity is correlated with the quantity of activated FX. The levels obtained are then compared to a sample of normal pooled plasma (20). Nowadays, many automated coagulometers have already modules for chromogenic FVIII assay (21). The test has a lower interlaboratory variability and a higher precision rate. The chromogenic assay is also not dependent on FVIII deficient plasma (22).

\section{Genetic testing and prenatal characterization}

As the diagnosis of hemophilia as early as possible is of utmost importance, genetic testing is recommended many times in affected individuals. It is also essential to identify women who might be carriers of a hemophilia-causing mutation (23).

Inversion of intron 22 in the F8 gene is present in 40$45 \%$ of severe cases of HA. As a result, a defective protein is produced which does not have any immunological or functional activity (24). Another common genetic mutation is the inversion of intron 1 , which is present in $4.8 \%$ of patients with severe HA (25). First, these two inversions are assessed by Southern blotting or polymerase chain reaction (PCR) $(25,26)$. If they are not present, a full DNA sequencing of the F8 gene is recommended (24). Currently, there are more than 2,500 unique variants of the F8 gene (27). $1 \%$ of severe cases of hemophilia type A and $3 \%$ of mild hemophilia type A cases have no mutations identified in the F8 gene $(28,29)$. In these cases, the role of post-transcriptionally control through non-coding RNAs, such as microRNAs is taken into consideration.

According to the European Association for Haemophilia and Allied Disorders (EAHAD) database, there are 1,113 unique variants of the F9 gene (30). Missense mutations comprise $58.4 \%$ of total mutations in the F9 gene, followed by frameshift (15.4\%), mutations of the splice site (7-9.4\%), and non-sense mutations (18-8.3\%). A small percentage of cases are caused also by the development of inhibitor antibodies (31). In order to evaluate the type of F9 mutation 


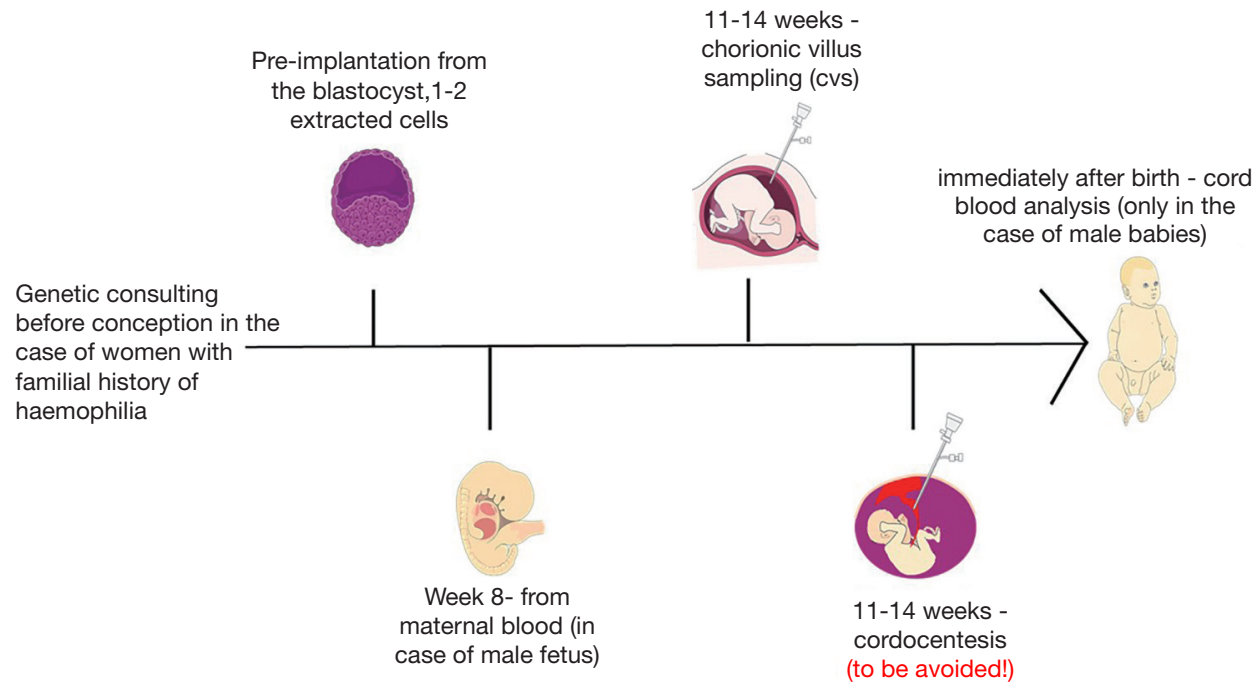

Figure 2 Genetic testing can be done at different timepoint in conception.

PCR is used for common variants (32) and sequencing for rare variants. The $\mathrm{F} 9$ gene sequencing can be performed through Sanger sequencing (33) or next generation sequencing (NGS) technologies (34).

Genetic counseling for prospective parents before conception is important. The carrier status of the future mother should be investigated if she has a history of frequent bleedings or she is coming from a family with a history of bleeding disorders. However, $50 \%$ of children with HA are born in families without a history of this disease. Preimplantation genetic testing is available to confirmed carriers of an F8 gene mutation, who can resort to in vitro fertilization to select a healthy embryo. This assessment is performed by PCR with DNA extracted from 1-2 cells from the embryo on the $3^{\text {rd }}$ day of development (35).

In the case of a male embryo, from maternal plasma, two targets located on the $\mathrm{Y}$ chromosome are investigated: the Testis-specific Y-encoded protein 1 (TSPY) and the Sexdetermining region Y protein (SRY) (36). At 11-14 weeks of gestation, future parents have the option of chorionic villus sampling (CVS), which is a transabdominal needle biopsy with ultrasound (US) guidance (37). After 18 weeks, there is the option of cordocentesis by aspirating fetal blood from the umbilical cord to measure the levels of coagulation factors. It has a greater risk for the fetus so is reserved only for those countries in which genetic testing is not possible (38). Measurement of FVIII from cord blood of male babies with mothers who carry the hemophilia gene is recommended immediately after birth. In this case there are no risks for the baby $(5,39)$. A timetable illustration of when genetic testing can take place is found in Figure 2.

People affected by hemophilia or having this disease in the family consider that prenatal genetic counseling is essential in allowing future parents to be informed. At the same time, it is important for all future parents that choose to do genetic testing to understand that hemophilia is no longer a lethal childhood disease and people with hemophilia can lead a long, good-quality life (40). There are various reports regarding the decision of pregnancy termination following a positive result of hemophilia diagnosis in the embryo/fetus, from $82 \%$ (38) to $27 \%$ (41) but the trend is downward, as the quality of life of hemophilic patients is continuously improving (40).

It is worth mentioning that in $30-50 \%$ of hemophilia cases are sporadic, meaning no family history (42). In approximately $30 \%$ of sporadic cases (i.e., no known family history of hemophilia), the variant (mutation) causing the disease cannot be found in the mother. However, with the conventional Sanger sequencing, carriership cannot be conclusively ruled out since she may be a mosaic not detected by this technique (39).

\section{The role of ultrasonography in diagnosis and monitoring}

Imaging and diagnostics offer an objective assessment of joint structural outcome with earlier changes of hemophilic arthropathy best assessed with either US or MR imaging. Both to detect and quantify relevant biomarkers of disease 
activity and degenerative damages by using scoring scales of increasing disease severity (43). With Doppler imaging, US may detect synovial hyperemia, the intrasynovial detection of signals of blood flow (44). In other chronic inflammatory disorders such as rheumatoid arthritis, the use of Doppler techniques is a mean to monitor disease activity (45).

Intrasynovial hyperemia assessed using Doppler imaging is uncommonly described in hemophilic patients. Rarely, a few blood flow signals are seen, suggesting mild hypervascularity that may not be considered relevant enough to redirect treatment and patient management (46). Low volume blood flow signals in the synovium from tiny intrasynovial vasculature and capillary circulation remain beyond the threshold of sensitivity of the Doppler systems. Also, a high variability in Doppler image interpretation leads to the need for high-end machines as to obtain a better performance and high interequipment variability (46). Using of Doppler imaging as a key tool to better predict the risk of hemorrhage and identify active disease seems to be problematic. US is not able to provide an adequate evaluation of the cartilage and subchondral bone, especially at the level of the weight-bearing areas, due to difficulties of access of the US beam. Medullary bone changes and subchondral cysts are not revealed with this technique. If we refer to the osteochondral surfaces exposed to the US beam, this technique has proved able to detect subtle echo textural changes, partial thickness losses through extensive derangement of the cartilage, with spatial resolution higher than surface-coiled MR imaging (47).

In Madrid, De la Corte-Rodriguez et al. conclude that point-of-care US (POC-US) used for patients with hemophilia enhances diagnostic accuracy and targeted treatments. POC-US should be investigated more fully to enable its widespread application (48). The same group, after properly understanding the POC-US, used the Hemophilia Early Arthropathy Detection with Ultrasound (HEAD-US) protocol to detect abnormal joints without a previous history of hemarthrosis, for clinically asymptomatic joints of hemophilic patients. They analyzed almost 1,000 joints of routine practice over 3 years and analyzed them based on history of hemarthrosis (HJHS 2.1) and HEAD-US examinations. They showed that HEADUS is more suitable than hemarthrosis records. The HJHS 2.1 scale is appropriate to detect the early signs of joint damage in patients with a hemophilia diagnosis (48). Thus, they concluded that US is valuable for the diagnosis of musculoskeletal diseases in haemophilia, being a fast, safe, available, comparative, effective, real-time technique that can aid confirm the clinical examination (49).

\section{Treatment strategy}

\section{"On demand" versus prevention therapy}

The lack of FVIII or FIX leads to spontaneous bleeding, especially in the joints. This can further cause hemophilic arthropathy (6). However, patients that are treated with primary prevention without signs of active bleedings, are less likely to acquire hemophilic arthropathy, unlike patients who are treated using the "on demand" factor $(7,8)$. Ideally, in an acute bleeding episode, treatment should be initiated as soon as possible $(7,50)$. For the "on demand" treatment, the quantity of factor needed depends on the type of joint bleed and the characteristics of each therapy (51). For recombinant FIX, 2-3 weekly administrations are required (52), whereas 3-4 administrations per week are recommended for recombinant FVIII (rFVIII) (53). For prophylaxis therapy, 1 weekly administration of FIX (54) and 1-2 doses/week in the case of FVIII are required (55).

There are three types of hemophilia prophylaxis: primary, secondary, and tertiary, each with its recommendation and purpose (Table 1). Still, the current prophylaxis therapy has limitations as it does not completely remove subclinical bleedings $(65,66)$, which in time can contribute to osteoarthritis (66).

\section{Strategies to improve prophylaxis therapy in hemophilia}

Prophylactic treatment is the optimum therapy as it prevents joint and muscle damage and allows the child or person with hemophilia to have a normal quality of life (Table 2).

As follows, the age and the bleeding phenotype should also be considered when it comes to dosage adjustment. Firstly, younger patients have metabolized the factor faster than the elderly, therefore they require more frequent administration of factor. In addition, elderly patients tend to be more inactive (72). Secondly, in the case of childhood hemophilia the beginning of the prophylaxis treatment should be initiated after the first episode of joint bleeding or immediately after the age of 3 , even in the absence of a prior bleeding episode (73). If the initiation is postponed, it could be necessary to engage a more intense regimen of secondary prophylaxis to reduce the bleeding frequency, but it will not stop or reverse the pre-existent joint damage (74). Moreover, elderly patients often present with comorbidities, such as diabetes, hypertension, or ischemic 
Table 1 Types of prophylaxis therapy in hemophilia and their recommendations

\begin{tabular}{|c|c|c|c|}
\hline Type of prophylaxis & Primary & Secondary & Tertiary \\
\hline \multirow[t]{8}{*}{ Purpose } & $\begin{array}{l}\text { - Prophylaxis of life-threatening } \\
\text { bleedings }\end{array}$ & $\begin{array}{l}\text { - Prophylaxis of life-threatening } \\
\text { bleedings }\end{array}$ & $\begin{array}{l}\text { - Prophylaxis of life-threatening } \\
\text { bleedings }\end{array}$ \\
\hline & - Maintaining joint integrity & - Reduce bleeding frequency & - Reduce bleeding frequency \\
\hline & - Minimize bleeding episodes & $\begin{array}{l}\text { - Prevent bleeding in the targeted } \\
\text { joints }\end{array}$ & $\begin{array}{l}\text { - Reduce bleedings in the targeted } \\
\text { joints }\end{array}$ \\
\hline & - Social status, educational & - Maintaining the quality of life & - Pain control \\
\hline & - Allows physical activities, sports & - Social status, educational & $\begin{array}{l}\text { - Reduces the bleedings associated } \\
\text { with other diseases }\end{array}$ \\
\hline & & - Allows physical activities, sports & $\begin{array}{l}\text { - Allows physiotherapy and orthopedic } \\
\text { surgery }\end{array}$ \\
\hline & & & - Improves the quality of life \\
\hline & & & - Improves social status and educational \\
\hline Reference & $(56-58)$ & $(59-62)$ & $(63,64)$ \\
\hline
\end{tabular}

Table 2 Factor dosing depending on the weight of the patient during prophylaxis therapy

\begin{tabular}{|c|c|c|}
\hline Type of dosage & Dosing & Reference \\
\hline $\begin{array}{l}\text { High/full-dose } \\
\text { (Malmo/Swedish) }\end{array}$ & $25-40 \mathrm{IU} / \mathrm{kg} 3 \times /$ week or at 2 days, from the age $1-2$, independently of bleeding history & $(67-69)$ \\
\hline $\begin{array}{l}\text { Escalating-dose } \\
\text { (Canadian) }\end{array}$ & $\begin{array}{l}50 \mathrm{IU} / \mathrm{kg} 1 \times / \text { week, with escalating at } 30 \mathrm{IU} 2 \times / \text { week, then } 25 \mathrm{IU} / \mathrm{kg} \text { at } 2 \text { days, depending on the bleeding } \\
\text { frequency. }\end{array}$ & $(70,71)$ \\
\hline
\end{tabular}

cardiomyopathy. In these situations, prophylaxis therapy has many other goals than just preventing joint bleedings, it also lowers the risk life-threatening complications cause be a bleeding episode associated with a comorbidity (75).

Regarding the bleeding phenotype, patients with the same level of factor can manifest different types of bleedings. A total of $10-15 \%$ of patients with severe hemophilia tend to have rare/mild types of bleedings. As follows the severity of hemophilia is not strictly related to factor level but also to the following aspects: type of genetic mutations (null or non-null) (42), the co-presence of a procoagulant mutation (such as in the factor $\mathrm{V}$ ) $(76,77)$, genetic variations of the inflammatory and immune response system (78). In all of these cases, the factors dose might be too high for the needs of the patient, because other aspects of bleeding phenotype are ignored.

A study on patients between 3-66 years concluded that the inter-individual variance is greater than the interoccasion variance thus body-weight and age give insufficient information to properly assess $\mathrm{PK}$ and determine 
dosage (79). An interesting conclusion of a study done by Björkman et al. was that in the PK difference in children versus elderly also comes also from the fact that children come for a blood sampling less frequent than elderly thus this co-variance should also be considered (80).

Classically, coagulation factor concentrate regimens are based on the notion that the PK characteristics of FVIII/ FIX products are roughly similar in all patients. Still, this theoretical model is in validated by clinical observations. Björkman et al. were the first to highlight the huge interindividual variability (2-4 times) concerning recovery and half-life, as PK data can help clinicians to personalize anti-hemophilic treatments particularly in two situations: surgery and prophylaxis. PK is considered to be a nonlinear time process that results from either the increasing or decreasing phase of drug concentrations. The drug concentration at a single time-point should not be considered in clinical practice. The drug concentration variations over time can be summarized using different PK parameters that are classified in two categories. The drug distribution is described by the volume of distribution $(\mathrm{Vd})$, the drug elimination (either metabolism and/or excretion) is defined by the elimination rate constant (ke), clearance $(\mathrm{Cl})$, and half-life $\left(\mathrm{T}^{1 / 2}\right)$. The second category corresponds to the parameters used in specific situations, as is the case for therapeutic drug monitoring. These parameters should be easier to estimate, and they need to be correlated with clinical events. The most used PK parameters in this category are the maximum concentration $\left(\mathrm{C}_{\max }\right)$ and the trough concentration $\left(\mathrm{C}_{\text {trough }}\right)$. In special situations, more complex parameters can be used, such as the area under the curve (AUC), for anti-hemophilic or antimicrobial agents. Web-based PK instruments are useful in helping the collaboration between the patient and the clinician, using a form a telemedicine, very useful in clinical scenarios as was the case of 2020 SARS-CoV-2 lockdown.

The pharmacokinetic (PK) of factor VIII is given by the response of the patient to the injection of factor VIII. $\mathrm{PK}$ is determined by frequent doses, calculated half-life of factor VIII, and the recovery test (81). PK analysis allows the exploration of prophylactic doses and range adaptation so that bleeding risks are kept to the minimum. 2-3 samples are needed at different time points and are estimated to give results similar to 9 or 11 measurements $(82,83)$. Currently, apps have been developed that can estimate the half-life of a factor in the patient plasma, based on the population pharmacokinetic data. Two examples of such apps are myPKFiT (Baxter Healthcare Corporation)_(https:// www.advate.com/mypkfit) and the Wapps-Hemo database (https://www.wapps-hemo.org/).

\section{Surgical interventions for the hemophilic patient}

Doctors form other specialties have many difficulties in managing hemophilic patients. For instance, the blood loss during a surgery has to be minimized, while maintaining blood fluidity and restricting the clotting to the site of vascular injury.

The treatment of hemophilic arthropathy is challenging also for the orthopedic department, as almost $80-90 \%$ of the bleeding episodes occur in the musculoskeletal system (84). These lesions include acute hemarthrosis (85), chronic synovitis (86), hemophilic arthropathy (87), intramuscular bleedings (87), hemophilic pseudotumors (88) and fractures (89).

In acute hemarthroses treatment should be administered intensively, therapy named enhanced on-demand treatment, until the resolution of symptoms. Ultrasonography is a Propper diagnostic technique to assess the evolution of acute hemarthrosis in hemophilia $(90,91)$.

The vicious circle of hemophilia arthropathy is presented in Figure 3.

Inappropriate management of acute articular lesions in the case of hemophilic patients can lead to chronic destruction of the surrounding tissues, with a negative impact on the patient's quality of life (Figure 4). No matter the musculoskeletal lesion, an important aspect is that the management requires a multidisciplinary team consisting of a hematologist, an anesthesiologist, an orthopedic surgeon, a physical and rehabilitation medicine specialist, and a physiotherapist, each providing an important contribution to the patient's final treatment outcome.

Hemophilic hemarthrosis is most frequently located in the knee, elbow, and ankle joints (8). Some studies suggest that the elbow and knee hemarthrosis are more frequent in patients older than 30 years, while ankle hemarthrosis occurs most likely in teenagers and young adults (92).

These lesions primarily require intravenous replacement of the deficient factor, limb immobilization in a noncircular splint or orthosis, non-weight-bearing after injury, the elevation of the affected joint, cryotherapy, and pain management drugs, such as nonsteroidal anti-inflammatory drugs, paracetamol, and opioids. If needed, joint aspiration can be performed in the case of severe hemarthrosis and only after the deficient factor replacement therapy. Joint aspiration is considered to be effective only if performed 


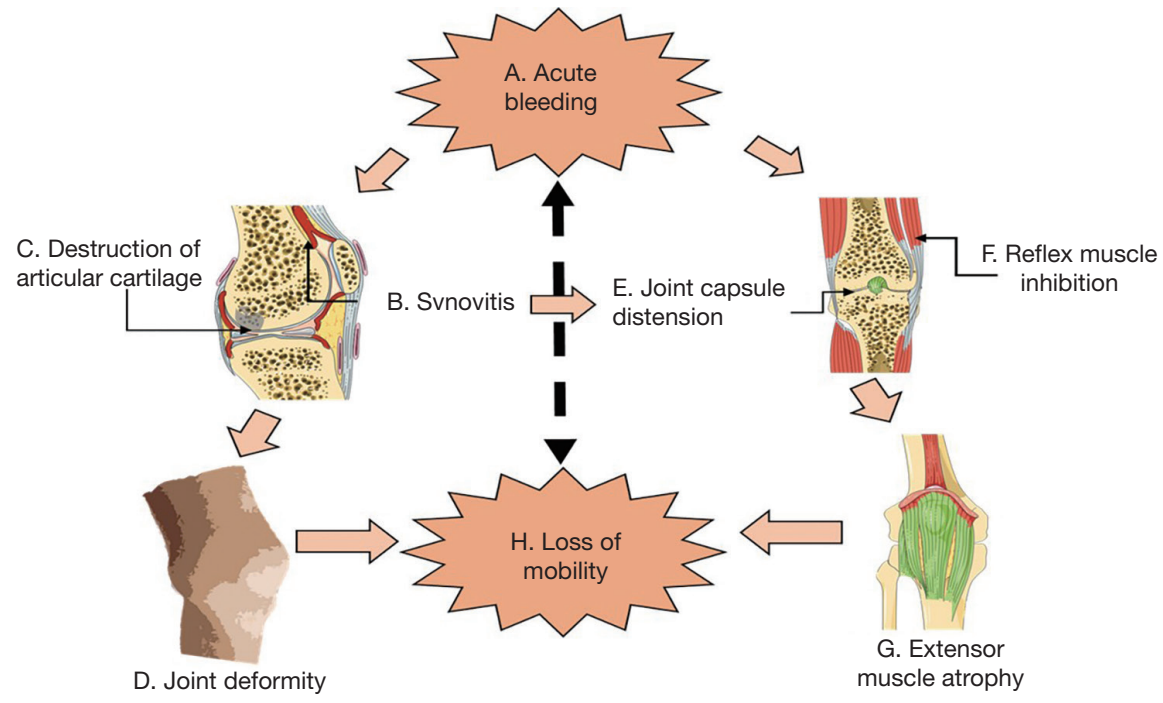

Figure 3 The cascade of events leading to hemophilic arthropathy. A. The acute bleeding in the joint space, results first in B. synovitis, which is followed by C. destruction of articular cartilage, which ultimately results in permanent D. joint deformity. Secondly, A. Acute bleeding causes E. Joint capsule distension, a condition which can also be the result of synovitis. The E. Joint capsule distension is followed by F. reflex muscle inhibition and G. Extensor muscle atrophy. All of these events ultimately lead to the H. Loss of mobility in the respective joint, which causes even more frequent episodes of acute bleedings.
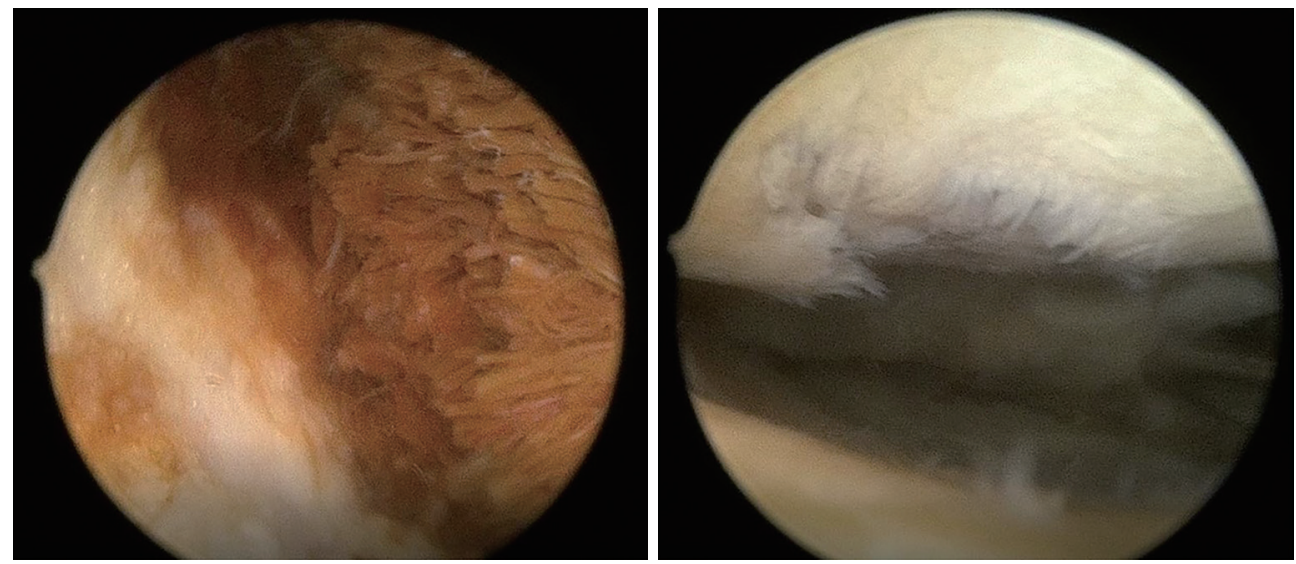

Figure 4 Chronic synovitis (left) and articular cartilage destruction (right) seen in a 25 -year-old patient with hemophilic arthropathy.

within the first 24 hours from bleeding episode onset $(8,93)$. Arthrocentesis must be carried out immediately after diagnosis of acute hemarthrosis in liquid phase. Patients must be infused with the deficient coagulation factor and instructed to observe relative rest until resolution of hemarthrosis (91).

Chronic synovitis is defined by the persistent inflammation of the synovial membrane within a joint. In the case of hemophilic patients, it is more often described in knee, elbow, and ankle joints (94). Chronic synovitis develops following a hemophilic hemarthrosis, where the synovial membrane is the main responsible for the resorption of hematoma (8). In the case of a massive hematoma, the synovial membrane becomes hypertrophic and releases various enzymes, which further increase synovial hypertrophy, producing articular cartilage destruction, and the epiphyseal growth plate hypertrophy (95). All of these changes explain the aspect of hemophilic arthropathy consisting of cartilage degeneration and morphologic bone changes. The management of chronic synovitis 
consists of radiosynovectomy (RS) (96) and arthroscopic synovectomy. As RS has a very low complication rate $(<1 \%)$ compared to arthroscopic synovectomy, it is the first treatment used for chronic synovitis (97). An arthroscopic synovectomy is a minimally invasive surgical procedure and consists of thorough debridement of the hypertrophic synovial membrane within the joint. Proper preoperative management by the hematologist is needed before the surgery. Although arthroscopy of the lower limb is generally performed with a spinal anesthesia, general anesthesia is preferred in the case of hemophilic patients. Careful consideration has to be taken as this surgical procedure in hemophilic patients has a higher risk of infection.

Hemophilic arthropathy is also defined by the articular cartilage destruction and bone changes following chronic synovitis. The injury leads to a decreased range of motion, pain during weight-bearing, and joint effusions (87).

Surgical options in these cases consist of arthroscopic debridement, open synovectomy, arthrodesis, and total joint replacements. The main risk for these surgical procedures is represented by infections (98). Based on our experience, the knee joint is the most frequently affected site of injury. In the case of young patients, arthroscopic debridement can offer pain relief and increase the range of motion. As a result, the need for a total knee replacement is postponed. Total knee replacement is a major elective procedure, with a $83-92 \%$ survival rate at ten years in the case of hemophilic patients $(90,99)$. The surgery is preferred to be performed under general anesthesia, tourniquet use until wound closure (100), capsule infiltration with a mixed solution, and tranexamic acid injection following capsule closure $(101,102)$. Moreover, hemostasis equilibrium is needed to prevent pseudoaneurysm postoperatively $(103,104)$.

The hemophilic elbow arthropathy is usually treated with a radial head excision and extensive open synovectomy (105). This procedure improves the range of motion and reduces pain in most patients. Nevertheless, due to radial head excision, a valgus deformity can occur, leading to an ulnar nerve lesion. This can be prevented or treated by an ulnar nerve release (106-109). Another surgical option for elbow hemophilic arthropathy is total elbow replacement. The downside of this procedure in hemophilic patients is the high complication rate (of up to $85 \%$ by some studies). Therefore, this type of surgery is not generally indicated $(90,110,111)$. Hemophilic ankle arthropathy can be surgically treated by: (I) arthroscopic debridement of the synovial hypertrophy and osteophytes $(112,113)$; (II) total ankle replacement $(114,115)$; (III) arthrodesis (116). Total ankle replacement has good overall results, but long-term data on a high number of patients are lacking. Therefore, arthroscopic debridement and osteophytes removal is the first-line treatment in hemophilic patients.

\section{Treatment options}

\section{Plasma-derived concentrates}

Plasma-derived concentrates are still used based on the opinion that recombinant factor treatment raises the risk of allogenic inhibitors development, in comparison with plasma-derived concentrates. Both plasma and recombinnat factors application poses the same risk of developing inhibitors (117), which is in agreement with the official Food and Drug Administration (FDA) and European Medicines Agency (EMA) guidelines. However, there is still a debate on this subject (118).

\section{Recombinant factors}

Nowadays the most often prescribed treatment for hemophilia is the recombinant factor. The availability of rFVIII has grown exponentially in the past years, due to the development of new forms of the factor (119). The third generation of rFVIII does not use proteins for stabilization, and it can either contain the full-length factor (Advate ${ }^{\circledR}$, Kovaltry $^{\circledR}$ ) or factor without B domain (Moroctocog alfa $\left(\right.$ Xyntha $\left.^{\circledR}\right)$, Turoctocog alfa $\left(\right.$ Novoeight $\left.^{\circledR}\right)$ ) (119). Regarding FIX, recombinant FIX (rFIX) products have been developed as well. Still, their properties are not substantially different from the original recombinant versions (120). The most used rFIX are BeneFIX $(121,122)$ and Rixubis (123).

\section{Extended half-life (EHL) factors}

The EHL factor, by decreasing the frequency of treatment administration increase treatment adherence and patients' compliance (5). rFVIIIFc (Eloctate) shows the deletion of a single B domain of FVIII fused with a dimeric Fc. This new feature allows it to stay in the bloodstream longer, hence delaying liposomal degradation $(119,124)$.

In order to extend half-lives, techniques like fusion to protein conjugates, chemical modification (PEGylation), and protein sequence modification are implemented. With these techniques, it is possible to extend half-lives of factor IX products 4- to 6-fold, while half-life extension of factor VIII products is limited to 1.5 - to 2-fold due to their 
interaction with von Willebrand factor. Methods to extend half-lives include fusion to protein conjugates, chemical modification, or protein sequence modification (125). For Fc-Fused FVIII, a single molecule of a B-domaindeleted rFVIII (human cell line) is covalently fused to the Fc domain of $\mathrm{IgG}_{1}$ (rFVIIIFc or efmoroctocog alfa). Efmoroctocog alfa (marketed as Elocta ${ }^{\circledR}$ in Europe) has been evaluated for safety, efficacy, and pharmacokinetics in two pivotal phase 3 studies (55). Terminal half-life of rFVIIIFc was extended 1.5 -fold as compared to non-EHL rFVIII. Several PEGylated FVIII products have been developed. They differ from each other by the PEGylation sites and the molecule length of FVIII. Rurioctacog alfa pegol (Adynovi ${ }^{\circledR}$ ) is created through controlled PEGylation of a full-length, unmodified rFVIII (synthesized in Chinese hamster ovary cells), in which approximately $60 \%$ of PEG chains are localized at the B-domain. BAX855 was evaluated in 138 PTPs with severe HA aged 12-65 years (126). For Fc-Fused FIX, rFIX-Fc (eftrenonacog alfa; Alprolix ${ }^{\circledR}$ ) was the first EHL approved by a regulatory body (US FDA) in March 2014. Eftrenonacog alfa is composed of a single recombinant FIX molecule (human cell line) fused to the dimeric $\mathrm{Fc}$ domain of $\operatorname{IgG}_{1}$ (127). In the pharmacokinetics subgroup rFIX-Fc exhibited a prolonged terminal halflife of 82 hours, the half-life of conventional FIX being 17 hours.

Polyethylene glycol (PEG) is a larges synthetic molecule that prolongs half-life by preventing proteolysis in the blood or by reducing receptor clearance binding, as well as low-density lipoproteins receptor-related protein 1 (LRP1) in FVIII, which is why the efficacy and safety of PEGylated rFVIII are increasingly tested (128). For instance, N8-GP (Turoctocog alfa pegol; Esperoct ${ }^{\circledR}$ ) is a glycoPEGylated rFVIII with increased safety upon administration and 1.6-fold increase in half-life compared to classical rFVIII, with up to 55 out of 186 patients experienced no bleeding episodes over the course of a treatment application of 5.4 years on average (129). There are different types of PEGylated FVIII products, which differ in size and methods used for the PEGylation (130). However, there are still concerns regarding the use of PEGylated biopharmaceuticals, one of them is related to the immunogenicity of the PEG molecule. Previous testing of anti-PEG IgM or IgG antibodies would be helpful to lower the risk of an immune reaction (131). However, PEGylated biotherapeutics can also accumulate in the body and cause organ damage. In an animal study on monkeys, it was proven that a twice per week administration of a
PEGylated protein for 3 months, resulted in its vacuolar accumulation in the macrophage residing in the kidney and choroid plexus. The accumulation did not subside even 2 months post administration of the last dosage. The $160 \mathrm{mg} / \mathrm{kg} /$ week dose was enough to cause long-term tissue damage (132). As follows, the EMA has still not approved its use for children under the age of 12 .

In the blood FVIII is bound to the von Willebrand factor (VWF) in a ratio of 1 molecule of FVIII to 50 molecules of VWF. The VWF stabilizes the FVIII plasmatic concentration and prolongs its half-life in circulation by six-fold, up to 8-12 hours (133). A novel type of FVIII was developed (rFVIIIFc-VWF-XTEN (BIVV001)) that allows the free circulation of rFVIII through a bound to the $\mathrm{D}^{\prime} \mathrm{D} 3$ domain of an exogenous VWF. The in vivo studies proved a half-life in animals of up to $34 \mathrm{~h}$ (134). BIVV001 is also an extended half-life rFVIII that through its independence from VWF has a 3 to 4 times increase in half-life in comparison to other conventional FVIII molecules, as proven in different animal models. BIVV001 has been designed so that the D'D3 domain and polypeptide XTEN inserts are removed during thrombin activation in the coagulation cascade. BIVV001 demonstrated a half-life of 37 hours, a substantial increase from the 13 hours half-life of conventional FVIII molecules (126).

Three EHL FIX proteins have been approved in recent years: recombinant factor IX (Alprolix), extended halflife factor IX (Idelvion) and glycoPEGylated recombinant factor IX (Rebinyn/Refixia). These three products have very different PK profiles due to the specific extravasal distribution of each one.

Alprolix ( $\mathrm{rFIXFc}$ ) compromises of a single FIX molecule bound to a dimeric Fc and uses the FcRn pathway to increase the time it remains in the bloodstream thus extending its half-life clearance to 82 hours (135). Idelvion (rIX-FP) is a rFIX conjugated with recombinant albumin but uses the same pathway to increase the time it remains in the bloodstream. It has a half-life mean of 91.4 hours $(55,136)$. The glycoPEGylated FIX (N9-GP; Rebinyn/ Refixia) is a compound of rFIX associated with a PEG molecule of $40 \mathrm{KDa}$. This molecule was designed so that the PEG part will be removed only through the enzymatic activity of FIX (1). However, with these drugs, there are concerns about the accumulation of PEG throughout time, especially during long-term administrations of a PEGylated drug. A clinical trial concluded that there is an initial increase in PEG level in the blood and afterward it reaches a plateau, remaining at the same concentration even after 
6.5 years. Children under the age of 7 accumulate PEG at a slower rate $(137,138)$.

\section{Bypass agents}

Patients who develop inhibitors, because of the substitute factor treatment (much more common in $\mathrm{HA}>30 \%$ then $\mathrm{HB}<3 \%$ ) are harder to be therapeutically managed. Two therapeutic options are available for patients with inhibitors. FEIBA, an activated prothrombin complex concentrate, meaning a plasma product, and FVIIa recombinant (rFVIIa) which bypass the role of the complex that activates FX. FEIBA is a drug accomplished from plasma, containing a mixture of activated and non-activated FX, FIX, FVII, and prothrombin (139). Recombinant factor VIIa (rFVIIa), known as eptacog alfa (Novo-Seven ${ }^{\circledR}$ ) is indicated for bleeding episodes and peri-operative management of HA or HB with inhibitors, congenital Factor VII (FVII) deficiency, and Glanzmann's thrombasthenia refractory to platelet transfusions, with or without antibodies to platelets and for the treatment of bleeding episodes and peri-operative management in adults with acquired hemophilia $(140,141)$.

The understanding of the coagulation cascade explains why no bypass agent can generate hemostasis as efficiently as substitute therapy with factor VIII and factor IX. Factor VIII and factor IX have important roles in the propagation phase of coagulation (at the surface of the activated platelet). During this time, the majority of FXa and thrombin is generated. This cannot be substituted by other proteins.

\section{FVIIIa mimetics}

Another therapeutic approach for HA is to replace the cofactor function of FVIIIa with an antibody that would serve as a bridge between FIXa and FX. Emicizumab has the man advantage of being administered subcutaneous, much more easily tolerated by patients. Importantly, these antibodies would not react with antibodies against FVIII, therefore they could be used as a prophylactic treatment in patients with HA who developed inhibitors and do not respond to induction of immune tolerance treatment. The biggest challenge of this approach is that FVIII has evolved greatly, over millions of years, with specific proteinphospholipid interactions that are regulated positively and negatively, therefore it is difficult to mimic the multiple functions of FVIIIa by an exogenous antibody (142).

The most advanced mimetic FVIII antibody is emicizumab, approved in 2017 by the FDA for the treatment of patients with HA with inhibitors based on the results of the HAVEN 1 study (61) and HAVEN 2 ongoing phase III study in pediatric patients with HA in inhibitors (143). Emicizumab can only be used for patients with HA. Emicizumab is a humanized IgG4 antibody that binds to FIXa on one side and FX on the other side. As follows, emicizumab binds FIXa to FX, but also binds FIX to $\mathrm{FXa}$, therefore it is a tetraspecific antibody. However, binding to the FIX zymogen may sequester the FIXa antibody, and binding to FXa may delay the assembly of the prothrombin-FXa-FVa complex. This may explain why emicizumab cannot fully support FVIII function (144). Patients in clinical trials with emicizumab, also needed FVIII substitution in acute bleeding episodes. Still, the results of the HAVEN 1 study demonstrate a significant decrease in acute bleeding episodes per year, from 28.3 per year in the placebo arm to 5.5 per year in the arm with patients prophylactically treated with emicizumab. Still, there were five reported serious side effects involving thrombosis, all occurring in patients to whom FEIBA was used concomitantly with emicizumab during acute episodes. Two of them were thromboembolic events and the other three were diagnosed as thrombotic microangiopathies (TMA). Signs of TMA include thrombocytopenia, autoimmune hemolytic anemia, and renal failure. In one patient with TMA, the bleeding could not be controlled, and was pronounced dead (61).

HAVEN 3 clinical trial was published by Mahlangu et al. (145) and randomly assigned 152 patients in a 2:2:1 ratio, who had been receiving episodic treatment with factor VIII to receive a subcutaneous maintenance dose of emicizumab. Emicizumab prophylaxis administered subcutaneously once weekly, or every 2 weeks is associated with a significantly lower bleeding rate than no prophylaxis among persons with HA without inhibitors. More than half the participants who received prophylaxis had no treated bleeding events. In an intraindividual comparison, emicizumab therapy led to a significantly lower bleeding rate than previous factor VIII prophylaxis.

In the HAVEN 4 study, evaluating emicizumab once every 4 weeks in patients with hemophilia with or without inhibitors, a clinical control of active bleeding episodes was reported. No thromboembolic or TMA events were reported. Five deaths have been reported in patients with emicizumab treated outside of the clinical trials as well as a report of anti-emicizumab antibody development (146).

When looking at all HAVEN 1-4 studies, with data from 401 pediatric and adult HA patients with/without factor 
VIII inhibitors enrolled, as well as a 970.3 patient-years of exposure, emicizumab prophylaxis maintained low bleed rates in HA patients of all ages and remains well tolerated, with no new safety concerns identified (147).

The HAVEN data was confirmed in Japan, in the openlabel study (HOHOEMI) study, evaluating the safety and efficacy of emicizumab in pediatric patients younger than 12 years with severe haemophilia A without factor VIII (FVIII) inhibitors, confirmed that emicizumab administration with four loading doses of $3 \mathrm{mg} / \mathrm{kg}$ every week followed by maintenance doses of $3 \mathrm{mg} / \mathrm{kg}$ every 2 weeks or $6 \mathrm{mg} / \mathrm{kg}$ every 4 weeks was efficacious and safe in pediatric patients with severe haemophilia A without inhibitors (148).

In the HAVEN 1 trial, thrombotic angiopathy was associated with higher FEIBA dosing, this recommendation preventing this complication is all future studies. Oldenburg et al. concluded that TMA or thrombosis was reported only in patients having received high cumulative doses of activated prothrombin complex concentrate for breakthrough bleeding while receiving emicizumab prophylaxis. Thus, the limiting use of FEIBA in patients who have bleeding events while receiving emicizumab prophylaxis (149).

\section{Inbibiting antitbrombotic patbways-introducing the $R \mathrm{NA}$ interference (RNAi)-based therapy}

Many groups and companies are exploring alternative therapies to achieve hemostasis, focusing on coagulation inhibitors. By inhibiting the negative regulators of the coagulation cascade, the thrombin produced should increase, generating enough thrombin to stop the bleeding $(9,150)$. This approach has been lately combined with another approach, RNA interference (RNAi) therapy.

RNAi is a molecular mechanism that has gained a lot of popularity in the last decade, with application in a great variety of human conditions. RNAi means that the exogenous introduction in the cell of an RNA sequence that has highly specific complementarity with an mRNA of a gene. Following mRNA-RNAi interaction, the mRNA is degraded and translation into protein no longer takes place (151).

RNAi is beginning to be applied also in hemophilia. A target of RNAi often tested is the antithrombin gene, more precisely the Antithrombin III (ATIII). Fitusiran is based on the RNAi technology. The drug contains an RNAi that binds to and degrades the ATIII mRNA thus the ATIII protein level decreases and the coagulation is re-balanced. The antithrombin is a glycoprotein able to bind to FIXa, FX, or thrombin and lower the circulating thrombin level. The therapy is currently in clinical trial testing. Up till now, an inhibition of $70 \%$ to $89 \%$ of antithrombin was reported (152). The sponsor (Alnylam) recently reported data from the phase II study of the open-label extension trial, which showed a significant reduction in the median number of bleeding seen in patients with hemophilia compared to their old regimens' treatment (150). During acute bleeding, patients taking Fitusiran needed a much lower dose of conventional products. The patients from the clinical trial used much lower doses of the conventional factor to treat acute bleedings, regardless of the product used. However, standard doses of treatment for acute bleeding episodes could result in the generation of excess thrombin with thromboembolic complications (153). The reported side effects were generally mild. However, the trial had some drawbacks in 2017 , in the initial phase as one of the patients died from a blood clot that led to a massive brain bleeding. Another serious adverse reaction was a rise in liver enzymes.

Fitusiran can be used for both HA and HB.

Another approach is the inhibition of Activated Protein C (APC), which normally cleaves FVIIIa and FVa. In patients with $\mathrm{HA}$ and $\mathrm{HB}$, the ability of APC to maintain the prothrombin-FVa-FXa complex is much more relevant. SerpinPC is an engineered serpin that specifically inhibits APC (activated protein C) (154). SerpinPC inhibits APC, thus allowing a higher stability of the prothrombin-FVaFXa complex that generates for a longer period of time plasma thrombin for patients with HA and HB. In a mouse model, SerpinPC was also able to stop episodes of acute bleedings $(155,156)$.

A trend towards decreasing bleeding tendency was observed and this preventative effect is being studied in phase II clinical trials, with additional data gathered to improve our understanding of the therapeutic window and potential for thrombosis (157).

\section{Gene therapies}

Since the original DNA cloning of FVIII and FIX, many people have proposed the use of gene therapy to replace missing factors in patients with HA and HB. After years of sporadic advances, there is considerable progress toward producing a factor in a vector that contains the replacement gene (158-160). Most clinical trials have focused on in 
Table 3 List of clinical trials using gene replacement therapy in hemophilia A and hemophilia B. Abbreviations: F8- factor VIII gene, F9- factor IX gene, AAV-adeno-associated virus

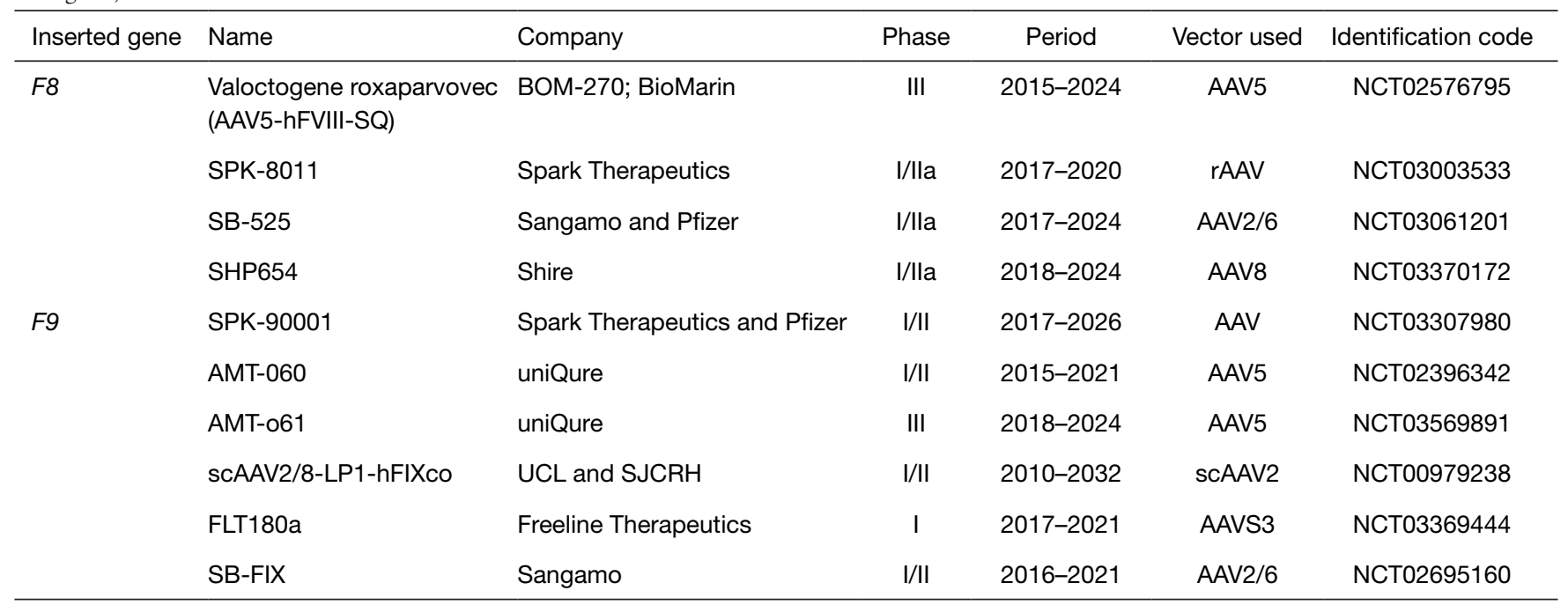

vivo gene transfer using vectors based on different adenoassociated virus (AAV) serotypes, although in some preclinical trials lentivirus vectors have also been used (161). AAV vectors have been proven in numerous studies to be safe and efficient in delivering the therapeutic gene. AAV have a simple structure, are not associated with any disease, and do not integrate in the genome. They have a single-stranded DNA genome and cannot infects the host in the absence of a co-infection (162). All the identified ongoing clinical trials on gene therapies in HA are presented in Table 3.

The most advanced clinical trial for FVIII gene therapy has been reported by BioMarin. Named valoctocogene roxaparvovec (BMN 270). It uses high doses of AAV and initially a wide range of factor activity was reported in the phase I/IIa study. One patient developed a $12 \%$ of factor VIII from normal, 4 patients developed 50\% from normal, and 2 patients had a peak of $250 \%$ from normal. All patients received prophylactic corticosteroids to prevent an anticapsid immune response, but some still had hepatocytolysis syndromes, but no loss of gene expression (163-165). The level of FVIII in the cohort with high dose AAV, at 104 weeks showed a decrease in the level of factor VIII, the highest being $150 \%$ of normal, and the median is $77 \%$ at 52 weeks. It should be noted that all patients with AAV antibodies were excluded from these clinical trials (163-165).

Although significant progress has been made in the area of gene therapy based on viral vectors, there are still major hurdles that impair the wide-scale clinical application of this technology. Research in gene therapy has a huge potential clinical impact in all areas of medicine, not only in hematology. Still, the technology has its limitation, especially related to target accessibility. AAV is now the vector of choice for most gene therapy options, as it was proven to be safe and well-tolerated in most clinical and preclinical settings it was investigated (146). New technology and novel genome editing options arises from the biology of bacteria that holds the promise of achieving precise modifications in the genome with simplicity and versatility that surpasses previous genome editing methods. This new technique, commonly named CRISPR/Cas9, which has brought Emmanuel Charpentier and Jennifer Doudna the 2020 Nobel Prize in Chemistry, has led to a rapid expansion of the biomedical field (158).

The latest advancements in gene therapy are focusing on human artificial chromosomes (HACs), which mimic the human chromosomes in terms of gene transcription regulation, allow the insertion of a large construct, contain epitopes of viral origin that prevent insertion into the host genome and allow independence of duplication and transcription (166). They also contain either $\alpha$-satellite sequences or (with a synthetic $\alpha$-satellite sequence and a tetracycline repressor (tetR) binding site, that permits the independent interaction with the kinetochore (167). Recently these advancements have moved from into the gene therapy of HA. Ponomartsev et al., proposed this year the use of alphoidtetO-HAC vector containing the F8 gene for the treatment of HA. The induced pluripotent cells (iPSC) from $\mathrm{FVII}^{\mathrm{y} /}$ mice fibroblasts were transfected 
with the alphoidtetO-HAC-FVIII with the help of reverse microcell-mediated chromosome transfer (MMCT) from $\mathrm{CHO}$ cells. The iPSC cells showed stable expression of the F8 gene and the vector remained independent. However, the production process is still very complicated, the induced HAC loses its integrity in the following generations of cells, and the FVIII still has a low level of production (168).

\section{Therapy of pain}

Pain is of key important for patients with hemophilia. Spontaneous joint bleeds cause the accumulation of intraarticular blood, resulting in swelling, impaired mobility, and severe acute pain (169). Repeated hemarthrosis progressively contribute to irreversible joint degeneration and later development of chronic hemophilic arthropathy, characterized by joint deformity, disability, and chronic pain (170). Pain in haemophilia can be either acute (hemarthrosis) or chronic (hemophilic arthropathy), or occur concurrently, thereby posing unique challenges to pain assessment and management. Pain is yet suboptimally treated, underlining the need to address this concern within the hemophilia comprehensive care setting. Though it is consensual that a thorough pain assessment is the basis for optimal pain management, the lack of specific and validated pain tools for hemophilia is also acknowledged, in spite of the abundance of disease-specific questionnaires for other painful conditions (171). Haemophilia-related pain has been assessed using distinct measures, from unidimensional Visual or Numerical Rating Scales (172), to multidimensional pain questionnaires like the McGill Pain Questionnaire (173) or the Brief Pain Inventory (174).

Efficient pain therapy is important to increase the quality of life in patients. For hemarthrosis, the following five steps are efficient to properly manage acute pain, as according to Rodriguez-Merchan et al. (175): intravenous infusion of FVIII/FIX, within 2 hours from the beginning of joint bleeding, till a plasma level not $<30-50 \%$ of the insufficient factor is attained, short-run repose of the painful articulation, local cryotherapy, joint aspiration of blood, and analgesic medication. The main step is substitution therapy with the insufficient coagulation.

Substitution therapy is of choice, preferably in the first 2 hours after the pain started. The aim is to achieve corrective coagulation factor levels of 30-50 IU dL. After replacement therapy is achieved, rest is of crucial importance. Cryotherapy may reduce swelling and decrease pain by its vasoconstricting effect, but arthrocentesis (joint aspiration) should be carried out in 2 days to preclude long-run joint impairment (176). When there is doubt as to whether hemarthrosis is present, ultrasonography is the next step for a good clinical diagnosis. The choosing of a particular analgesic treatment will be determined by the severity of pain and on the peculiarities of the patient $(177,178)$. For stronger pain, metamizole is an option. In particular cases, soft opioids such as codeine or tramadol may be employed. For atrocious pain, the optimal medication must be morphine hydrochloride, either continuous infusion or a PCA pump, based on the age, mental condition, and grade of acceptance of the patient. Epidural blocks with bupivacaine and fentanyl may be very effective.

For chronic pain, reported recommendations are separated over the ability of acetaminophen and nonsteroidal anti-inflammatory medications (NSAIDs) as firstline pharmacologic treatment of osteoarthritis. Tramadol is more frequently used for the treatment of osteoarthritis. Thus, in contrast to NSAIDs, tramadol does not cause gastrointestinal bleeding or renal complications, and does not cause injury to the articular cartilage (179). Opioids can be a good alternative if patients with knee osteoarthritis have intense pain or if other analgesic medication is contraindicated. Still, the data related to their efficacy and security are inconsistent (180-183). Fransen et al. (181) stated that land-based therapeutic exercise is beneficial for people with osteoarthritis in terms of reduced joint pain for at least two six months.

\section{Conclusions}

In conclusion, a highly specific and accurate diagnosis is essential for the optimal and efficient management of both HA and HB. Musculoskeletal complications are the most common manifestation and the main cause of the discomfort, poor quality of life, physical and mental disability. Prompt treatment of each bleeding episode can prevent joint degradation and the need for orthopedic interventions. Standard prophylaxis based on body weight should give way to cost-effective personalized therapy. Age, pharmacokinetics, bleeding phenotype, joint status, adherence, physical activity, personal goals are all factors that should be considered when individualizing therapy. For patients with/without factor VIII inhibitors, emicizumab prophylaxis maintains low bleed rates in HA patients of all ages and remains well tolerated, with no new safety concerns identified. Alternative therapies are also of good practical use, improving the quality of life in patients with 
HA and rare bleeding disorders.

A patient-centered regimen is considered optimal. Recombinant factors still remain the standard of care in hemophilia, however they pose a challenge to treatment adherence because they have short half-life, which where the extended half-life factors come with the solution, increasing the half-life to 96 hours. Gene therapies have a promising future with proven beneficial effects in clinical trials, however, a better vector must be found since AAV has the major threat to transduce the hepatocytes and cause hepatocytolysis syndromes.

\section{Acknowledgments}

Funding: Ionut Hotea is funded by an internal grant of the Iuliu Hatieganu University-School of Doctoral Studies (PCD 2018-2021). This work is also supported by an international grant awarded by the Novo Nordisk Haemophilia Foundation 2020-2021 "Strengthen haemophilia care in the north and establish a national registry in Romania“ awarded to the Romanian Society of Hematology, as well as by grants from the Romanian Ministry of Research and Innovation, CCCDI-UEFISCDI, Project No. PN-III-P4-ID-PCCF-2016-0112 within PNCDI III, for Young Research Teams 2020-2022 (Grant No. PN-III-P1-1.1-TE-2019-0271), and by an international collaborative grant of the European Economic Space between Romania and Iceland 2020-2022 (Grant No. 19-COP-0031).

\section{Footnote}

Peer Review File: Available at https://dx.doi.org/10.21037/ atm-21-747

Conflicts of Interest: All authors have completed the ICMJE uniform disclosure form (available at https://dx.doi. org/10.21037/atm-21-747). CT serves as an unpaid editorial board member of Annals of Translational Medicine from Nov 2019 to Oct 2021. The other authors have no conflicts of interest to declare.

Ethical Statement: The authors are accountable for all aspects of the work in ensuring that questions related to the accuracy or integrity of any part of the work are appropriately investigated and resolved.

Open Access Statement: This is an Open Access article distributed in accordance with the Creative Commons Attribution-NonCommercial-NoDerivs 4.0 International License (CC BY-NC-ND 4.0), which permits the noncommercial replication and distribution of the article with the strict proviso that no changes or edits are made and the original work is properly cited (including links to both the formal publication through the relevant DOI and the license). See: https://creativecommons.org/licenses/by-nc-nd/4.0/.

\section{References}

1. Pilli VS. Understanding the Clotting Cascade, Regulators, and Clinical Mod-ulators of Coagulation. In Hematology - Latest Research and Clinical Advances; Guenova M, Balatzenko G. editors. InTech, 2018

2. Al-Allaf FA, Taher MM, Abduljaleel Z, et al. Molecular Analysis of Factor VIII and Factor IX Genes in Hemophilia Patients: Identification of Novel Mutations and Molecular Dynamics Studies. J Clin Med Res 2017;9:317-31.

3. Bolton-Maggs PHB, Pasi KJ. Haemophilias A and B. Lancet 2003;361:1801-9.

4. Makris M, Oldenburg J, Mauser-Bunschoten EP, et al. The Definition, Diagnosis and Management of Mild Hemophilia A: Communication from the SSC of the ISTH. J Thromb Haemost 2018;16:2530-3.

5. Srivastava A, Brewer AK, Mauser-Bunschoten EP, et al. Guidelines for the Management of Hemophilia. Haemophilia 2013;19:e1-47.

6. Cross S, Vaidya S, Fotiadis N. Hemophilic Arthropathy: A Review of Imaging and Staging. Semin Ultrasound CT MR 2013;34:516-24.

7. Rodriguez-Merchan, EC. Musculoskeletal Complications of Hemophilia. HSS J 2010;6:37-42.

8. Lobet S, Hermans C, Lambert C. Optimal Management of Hemophilic Ar-thropathy and Hematomas. J Blood Med 2014:5:207-18.

9. Franchini M, Mannucci PM. Non-Factor Replacement Therapy for Hemophilia: A Current Update. Blood Transfusion 2018;16:457-61.

10. Witmer C, Young G. Factor VIII Inhibitors in Hemophilia A: Rationale and Latest Evidence. Ther Adv Hematol 2013;4:59-72.

11. Meeks SL, Batsuli G. Hemophilia and Inhibitors: Current Treatment Options and Potential New Therapeutic Approaches. Hematology Am Soc Hematol Educ Program 2016;2016:657-62.

12. Mannucci PM. Hemophilia Therapy: The Future Has 
Begun. Haematologica 2020;105:545-53.

13. Ng VL. Prothrombin Time and Partial Thromboplastin Time Assay Considera-tions. Clin Lab Med 2009;29:253-63.

14. Shikdar S, Vashisht R, Bhattacharya PT. International Normalized Ratio (INR). In StatPearls; StatPearls Publishing: Treasure Island (FL), 2021.

15. Mansouritorghabeh H. Clinical and Laboratory Approaches to Hemophilia a. Iran J Med Sci 2015;40:194-205.

16. Winter WE, Flax SD, Harris NS. Coagulation Testing in the Core Laboratory. Lab Med 2017;48:295-313.

17. Kitchen S, Preston FE. The Therapeutic Range for Heparin Therapy: Relation-ship between Six Activated Partial Thromboplastin Time Reagents and Two Heparin Assays. Thromb Haemost 1996;75:734-9.

18. Benzon HT, Park M, McCarthy RJ, et al. Mixing Studies in Patients With Pro-longed Activated Partial Thromboplastin Time or Prothrombin Time. Anesth Analg 2019;128:1089-96.

19. Goodeve AC. Laboratory Methods for the Genetic Diagnosis of Bleeding Dis-orders. Clin Lab Haematol 1998;20:3-19.

20. Tripodi A, Santoro RC, Testa S, et al. Position Paper on Laboratory Testing for Patients with Haemophilia. A Consensus Document from SISET, AICE, SIBioC and SIPMeL. Blood Transfus 2019;17:229-36.

21. Bowyer AE, Duncan EM, Antovic JP. Role of Chromogenic Assays in Haemo-philia A and B Diagnosis. Haemophilia 2018;24:578-83.

22. Van den Bossche D, Peerlinck K, Jacquemin M. New Challenges and Best Practices for the Laboratory Monitoring of Factor VIII and Factor IX Replacement. Int J Lab Hematol 2018;40 Suppl 1:21-9.

23. Swystun LL, James PD. Genetic Diagnosis in Hemophilia and von Willebrand Disease. Blood Rev 2017;31:47-56.

24. Peyvandi F. Carrier Detection and Prenatal Diagnosis of Hemophilia in Devel-oping Countries. Semin Thromb Hemost 2005;31:544-54.

25. Kessler CM, Knöbl P. Acquired Haemophilia: An Overview for Clinical Practice. Eur J Haematol 2015;95 Suppl 81:36-44.

26. Rossetti LC, Radic CP, Larripa IB, et al. Genotyping the Hemophilia Inversion Hotspot by Use of Inverse PCR. Clin Chem 2005;51:1154-8.

27. McVey JH, Rallapalli PM, Kemball-Cook G, et al. The European Association for Haemophilia and Allied Disorders (EAHAD) Coagulation Factor Variant Databases: Important Resources for Haemostasis
Clinicians and Researchers. Haemophilia 2020;26:306-13.

28. El-Maarri O, Herbiniaux U, Graw J, et al. Analysis of MRNA in Hemophilia A Patients with Undetectable Mutations Reveals Normal Splicing in the Factor VIII Gene. J Thromb Haemost 2005;3:332-9.

29. Johnsen JM, Fletcher SN, Huston H, et al. Novel Approach to Genetic Analysis and Results in 3000 Hemophilia Patients Enrolled in the My Life, Our Future Initia-tive. Blood Adv 2017;1:824-34.

30. Rallapalli PM, Kemball-Cook G, Tuddenham EG, et al. An Interactive Mutation Database for Human Coagulation Factor IX Provides Novel Insights into the Pheno-types and Genetics of Hemophilia B. J Thromb Haemost 2013;11:1329-40.

31. Castaman G, Matino D. Hemophilia A and B: Molecular and Clinical Similari-ties and Differences. Haematologica 2019;104:1702-9.

32. Enayat MS, Karimi M, Chana G, et al. Mutation Analysis in F9 Gene of 17 Families with Haemophilia B from Iran. Haemophilia 2004;10:751-5.

33. Lv X, Li T, Li H, et al. Genetic Analysis of a Hemophilia B Family with a Novel F9 Gene Mutation: A STROBECompliant Article. Medicine (Baltimore) 2019;98:e15688.

34. Yi S, Yang Q, Zuo Y, et al. A Novel Missense Mutation in F9 Gene Causes Hemophilia B in a Family with Clinical Variability. Blood Coagul Fibrinolysis 2020;31:121-6.

35. Dreesen J, Destouni A, Kourlaba G, et al. Evaluation of PCR-Based Preimplan-tation Genetic Diagnosis Applied to Monogenic Diseases: A Collaborative ESHRE PGD Consortium Study. Eur J Hum Genet 2014;22:1012-8.

36. Avent ND, Chitty LS. Non-Invasive Diagnosis of Fetal Sex; Utilisation of Free Fetal DNA in Maternal Plasma and Ultrasound. Prenat Diagn 2006;26:598-603.

37. Wells D, Delhanty JD. Preimplantation Genetic Diagnosis: Applications for Molecular Medicine. Trends Mol Med 2001;7:23-30.

38. Balak DMW, Gouw SC, Plug I, et al. Prenatal Diagnosis for Haemophilia: A Nationwide Survey among Female Carriers in the Netherlands. Haemophilia 2012;18:584-92.

39. Lannoy N, Hermans C. Genetic Mosaicism in Haemophilia: A Practical Review to Help Evaluate the Risk of Transmitting the Disease. Haemophilia 2020;26:375-83.

40. Boardman FK, Hale R, Gohel R, et al. Preventing Lives Affected by Hemophilia: A Mixed Methods Study of the Views of Adults with Hemophilia and Their Families toward Genetic Screening. Mol Genet Genomic Med 2019;7:e618. 
41. Kadir RA, Sabin CA, Goldman E, et al. Reproductive Choices of Women in Families with Haemophilia. Haemophilia 2000;6:33-40.

42. Carcao MD, van den Berg HM, Ljung R, et al. Correlation between Phenotype and Genotype in a Large Unselected Cohort of Children with Severe Hemophilia A. Blood 2013;121:3946-52.

43. Maclachlan J, Gough-Palmer A, Hargunani R, et al. Haemophilia Imaging: A Review. Skeletal Radiol 2009;38:949-57.

44. Kidder W, Nguyen S, Larios J, et al. Point-of-Care Musculoskeletal Ultrasound Is Critical for the Diagnosis of Hemarthroses, Inflammation and Soft Tissue Abnormalities in Adult Patients with Painful Haemophilic Arthropathy. Haemophilia 2015;21:530-7.

45. Newman JS, Laing TJ, McCarthy CJ, et al. Power Doppler Sonography of Syn-ovitis: Assessment of Therapeutic Response--Preliminary Observations. Radiology 1996;198:582-4.

46. Di Minno MN, Ambrosino P, Quintavalle G, et al. Assessment of Hemophilic Arthropathy by Ultrasound: Where Do We Stand? Semin Thromb Hemost 2016;42:541-9.

47. van Vulpen LFD, Holstein K, Martinoli C. Joint Disease in Haemophilia: Pathophysiology, Pain and Imaging. Haemophilia 2018;24 Suppl 6:44-9.

48. De la Corte-Rodriguez H, Rodriguez-Merchan EC, Jimenez-Yuste V. Point-of-Care Ultrasonography in Orthopedic Management of Hemophilia: Multiple Uses of an Effective Tool. HSS J 2018;14:307-13.

49. Querol F, Rodriguez-Merchan EC. The Role of Ultrasonography in the Diagnosis of the Musculo-Skeletal Problems of Haemophilia. Haemophilia 2012;18:e215-26.

50. Saulyte Trakymiene S, Steen Carlsson K. On-Demand Treatment in Persons with Severe Haemophilia. Eur J Haematol Suppl 2014;76:39-47.

51. Nugent D, O'Mahony B, Dolan G. International Haemophilia Access Strategy Council Value of Prophylaxis vs On-Demand Treatment: Application of a Value Framework in Hemophilia. Haemophilia 2018;24:755-65.

52. Mancuso ME, Mahlangu JN, Pipe SW. The Changing Treatment Landscape in Haemophilia: From Standard Half-Life Clotting Factor Concentrates to Gene Editing. Lancet 2021;397:630-40.

53. Wang C, Young G. Clinical Use of Recombinant Factor VIII Fc and Recombinant Factor IX Fc in Patients with Haemophilia A and B. Haemophilia 2018;24:414-9.

54. Djambas Khayat C. Once-Weekly Prophylactic Dosing of Recombinant Factor IX Improves Adherence in Hemophilia B. J Blood Med 2016;7:275-82.

55. Mahlangu J, Powell JS, Ragni MV, et al. Phase 3 Study of Recombinant Factor VIII Fc Fusion Protein in Severe Hemophilia A. Blood 2014;123:317-25.

56. Coppola A, Di Capua M, De Simone C. Primary Prophylaxis in Children with Haemophilia. Blood Transfus 2008;6 Suppl 2:S4-11.

57. Ljung RCR. Prevention and Management of Bleeding Episodes in Children with Hemophilia. Paediatr Drugs 2018;20:455-64.

58. Wang M, Álvarez-Román MT, Chowdary P, et al. Physical Activity in Individ-uals with Haemophilia and Experience with Recombinant Factor VIII Fc Fusion Pro-tein and Recombinant Factor IX Fc Fusion Protein for the Treatment of Active Pa-tients: A Literature Review and Case Reports. Blood Coagul Fibrinolysis 2016;27:737-44.

59. Oldenburg J. Optimal Treatment Strategies for Hemophilia: Achievements and Limitations of Current Prophylactic Regimens. Blood 2015;125:2038-44.

60. Sidharthan N, Sudevan R, Narayana Pillai V, et al. LowDose Prophylaxis for Children with Haemophilia in a Resource-Limited Setting in South India-A Clinical Audit Report. Haemophilia 2017;23:e382-4.

61. Gupta S, Shapiro AD. Optimizing Bleed Prevention throughout the Lifespan: Womb to Tomb. Haemophilia 2018;24 Suppl 6:76-86.

62. Zanon E, Tagliaferri A, Pasca S, et al. Physical Activity Improved by Adherence to Prophylaxis in an Italian Population of Children, Adolescents and Adults with Severe Haemophilia A: The SHAPE Study. Blood Transfus 2020;18:152-8.

63. Gringeri A, Lambert T, Street A, et al. Adolescent/Adult Prophylaxis Expert Working Group of the International Prophylaxis Study Group Tertiary Prophylaxis in Adults: Is There a Rationale? Haemophilia 2012;18:722-8.

64. Hua B, Lian X, Li K, et al. Low-Dose Tertiary Prophylactic Therapy Reduces Total Number of Bleeds and Improves the Ability to Perform Activities of Daily Living in Adults with Severe Haemophilia A: A Single-Centre Experience from Bei-jing. Blood Coagul Fibrinolysis 2016;27:136-40.

65. Rocino A, Franchini M, Coppola A. Treatment and Prevention of Bleeds in Haemophilia Patients with Inhibitors to Factor VIII/IX. J Clin Med 2017;6:46.

66. Gringeri A, Ewenstein B, Reininger A. The Burden of Bleeding in Haemophilia: Is One Bleed Too Many? Haemophilia 2014;20:459-63. 
67. Ar MC, Vaide I, Berntorp E, et al. Methods for Individualising Factor VIII Dosing in Prophylaxis. Eur J Haematol Suppl 2014;76:16-20.

68. Fischer K, Steen Carlsson K, Petrini P, et al. IntermediateDose versus High-Dose Prophylaxis for Severe Hemophilia: Comparing Outcome and Costs since the 1970s. Blood 2013;122:1129-36.

69. Nilsson IM, Berntorp E, Löfqvist T, et al. Twenty-Five Years' Experience of Prophylactic Treatment in Severe Haemophilia A and B. J Intern Med 1992;232:25-32.

70. Feldman BM, Rivard GE, Babyn P, et al. Tailored Frequency-Escalated Primary Prophylaxis for Severe Haemophilia A: Results of the 16-Year Canadian Hemophilia Prophylaxis Study Longitudinal Cohort. Lancet Haematol 2018;5:e252-60.

71. Dover S, Blanchette VS, Wrathall D, et al. Hemophilia Prophylaxis Adherence and Bleeding Using a Tailored, Frequency-Escalated Approach: The Canadian Hemophilia Primary Prophylaxis Study. Res Pract Thromb Haemost 2020;4:318-25.

72. van Dijk K, van der Bom JG, Lenting PJ, et al. Factor VIII Half-Life and Clinical Phenotype of Severe Hemophilia A. Haematologica 2005;90:494-8.

73. Blanchette VS, Key NS, Ljung LR, et al. Definitions in Hemophilia: Commu-nication from the SSC of the ISTH. J Thromb Haemost 2014;12:1935-9.

74. Tagliaferri A, Di Perna C, Rivolta GF. Secondary Prophylaxis in Adolescent and Adult Haemophiliacs. Blood Transfus 2008;6 Suppl 2:s17-20.

75. Franchini M, Tagliaferri A, Mannucci PM. The Management of Hemophilia in Elderly Patients. Clin Interv Aging 2007;2:361-8.

76. Nichols WC, Amano K, Cacheris PM, et al. Moderation of Hemophilia A Phe-notype by the Factor V R506Q Mutation. Blood 1996;88:1183-7.

77. Kurnik K, Kreuz W, Horneff S, et al. Effects of the Factor V G1691A Mutation and the Factor II G20210A Variant on the Clinical Expression of Severe Hemophilia A in Children--Results of a Multicenter Studys. Haematologica 2007;92:982-5.

78. de Alencar JB, Macedo LC, de Barros MF, et al. Importance of Immune Re-sponse Genes in Hemophilia A. Rev Bras Hematol Hemoter 2013;35:280-6.

79. Björkman S, Folkesson A, Jönsson S. Pharmacokinetics and Dose Requirements of Factor VIII over the Age Range 3-74 Years: A Population Analysis Based on 50 Patients with Long-Term Prophylactic Treatment for Haemophilia A. Eur J Clin Pharmacol 2009;65:989-98.
80. Björkman S, Blanchette VS, Fischer K, et al. Comparative Pharmacokinetics of Plasma- and Albumin-Free Recombinant Factor VIII in Children and Adults: The Influence of Blood Sampling Schedule on Observed AgeRelated Differences and Implications for Dose Tailoring. J Thromb Haemost 2010;8:730-6.

81. Björkman S, Oh M, Spotts G, et al. Population Pharmacokinetics of Recombi-nant Factor VIII: The Relationships of Pharmacokinetics to Age and Body Weight. Blood 2012;119:612-8.

82. Brekkan A, Berntorp E, Jensen K, et al. Population Pharmacokinetics of Plas-ma-Derived Factor IX: Procedures for Dose Individualization. J Thromb Haemost 2016;14:724-32.

83. Björkman S, Collins P. Project on Factor VI I I/Factor IX Pharmacokinetics of the Factor VIII/Factor IX Scientific and Standardization Committee of The Isth Measurement of Factor VIII Pharmacokinetics in Routine Clinical Practice. J Thromb Haemost 2013;11:180-2.

84. Atilla B, Güney-Deniz H. Musculoskeletal Treatment in Haemophilia. EFORT Open Rev 2019;4:230-9.

85. Simpson ML, Valentino LA. Management of Joint Bleeding in Hemophilia. Expert Rev Hematol 2012;5:459-68.

86. Ghosh K, Ghosh K. Management of Chronic Synovitis in Patients with Hemo-philia: With Special Reference to Developing Countries. Indian J Hematol Blood Transfus 2008;24:151-4.

87. Melchiorre D, Manetti M, Matucci-Cerinic M. Pathophysiology of Hemophilic Arthropathy. J Clin Med 2017;6:63.

88. Rodriguez-Merchan, EC. Hemophilic Pseudotumors: Diagnosis and Manage-ment. Arch Bone Jt Surg 2020;8:121-30.

89. Wolff LJ, Lovrien EW. Management of Fractures in Hemophilia. Pediatrics 1982;70:431-6.

90. Rodriguez-Merchan EC, De la Corte-Rodriguez H, Jimenez-Yuste V. Joint As-piration of Acute Tense Knee Haemarthroses in Adult Haemophilia A Patients. Thromb Res 2013;132:778-9.

91. De la Corte-Rodriguez H, Rodriguez-Merchan EC, Alvarez-Roman MT, et al. Accelerating Recovery from Acute Hemarthrosis in Patients with Hemophilia: The Role of Joint Aspiration. Blood Coagul Fibrinolysis 2019;30:111-9.

92. Stephensen D, Tait RC, Brodie N, et al. Changing Patterns of Bleeding in Pa-tients with Severe Haemophilia A. Haemophilia 2009;15:1210-4. 
93. Majid Z, Tahir F, Qadar LT, et al. Hemophilia A with a Rare Presentation of Hemarthrosis and Arthropathy Involving Multiple Joints in a Young Male Child. Cureus 2019;11:e4524.

94. Calcaterra I, Iannuzzo G, Dell'Aquila F, Di Minno MND. Pathophysiological Role of Synovitis in Hemophilic Arthropathy Development: A Two-Hit Hypothesis. Front Physiol 2020;11:541.

95. Wyseure T, Mosnier LO, von Drygalski A. Advances and Challenges in He-mophilic Arthropathy. Semin Hematol 2016,53:10-9.

96. Shinto AS, Kamaleshwaran KK, Chakraborty S, et al. Radiosynovectomy of Painful Synovitis of Knee Joints Due to Rheumatoid Arthritis by Intra-Articular Administration of (177)Lu-Labeled Hydroxyapatite Particulates: First Human Study and Initial Indian Experience. World J Nucl Med 2015;14:81-8.

97. De la Corte-Rodriguez H, Rodriguez-Merchan EC, Jimenez-Yuste V. Radio-synovectomy in Hemophilia: Quantification of Its Effectiveness through the Assessment of 10 Articular Parameters. J Thromb Haemost 2011;9:928-35.

98. Rodriguez-Merchan, EC.; Valentino, L.A. Orthopedic Disorders of the Knee in Hemophilia: A Current Concept Review. World J Orthop 2016;7:370-5.

99. Silva M, Luck JV. Long-Term Results of Primary Total Knee Replacement in Patients with Hemophilia. J Bone Joint Surg Am 2005;87:85-91.

100. Rodríguez-Merchán EC. Total Knee Arthroplasty in Hemophilic Arthrop-athy. Am J Orthop (Belle Mead NJ) 2015;44:E503-7.

101. Rodriguez-Merchan EC, Romero-Garrido JA, GomezCardero P. Multi-modal Blood Loss Prevention Approach Including Intra-Articular Tranexamic Acid in Primary Total Knee Arthroplasty for Patients with Severe Haemophilia A. Haemo-philia 2016;22:318-20.

102. Rodriguez-Merchan EC, Encinas-Ullan CA, GomezCardero P. In-tra-Articular Tranexamic Acid in Primary Total Knee Arthroplasty Decreases the Rate of Post-Operative Blood Transfusions in People with Hemophilia: A Retro-spective Case-Control Study. HSS J 2020;16:218-21.

103. Kickuth R, Anderson S, Peter-Salonen K, et al. Hemophilia A Pseudoan-eurysm in a Patient with High Responding Inhibitors Complicating Total Knee Arthroplasty: Embolization: A Cost-Reducing Alternative to Medical Therapy. Cardiovasc Intervent Radiol 2006;29:1132-5.
104. Rodriguez-Merchan EC, Jimenez-Yuste V, GomezCardero P, Rodriguez T. Severe Postoperative Haemarthrosis Following a Total Knee Replacement in a Haemophiliac Patient Caused by a Pseudoaneurysm: Early Treatment with Arterial Embolization. Haemophilia 2014;20:e86-9.

105.Merchan EC, Galindo E, Magallon M, et al. Resection of the Radial Head and Partial Open Synovectomy of the Elbow in the Young Adult with Haemophilia: Long-Term Results. Haemophilia 1995;1:262-6.

106. Atalar AC, Koc B, Birisik F, et al. Benefits of Radial Head Excision in Patients with Haemophilia: Mid-Term Functional Results. Haemophilia 2016;22:e25-9.

107. Silva M, Luck JV. Radial Head Excision and Synovectomy in Patients with Hemophilia. Surgical Technique. J Bone Joint Surg Am 2008;90 Suppl 2 Pt 2:254-61.

108. Bouhelo-Pam KPB, Louckou EAM, Abdulrazak S, et al. Ulnar Nerve En-trapment Complicating Radial Head Excision. Int J Surg Case Rep 2017;41:511-5.

109. Heim M, Beeton K, Blamey G, et al. Management of the Elbow Joint. Haemophilia 2012;18 Suppl 4:101-4.

110. Kamineni S, Adams RA, O’Driscoll SW, et al. Hemophilic Arthropathy of the Elbow Treated by Total Elbow Replacement. A Case Series. J Bone Joint Surg Am 2004;86:584-9.

111. Dale TM, Saucedo JM, Rodriguez-Merchan EC. Total Elbow Arthroplasty in Haemophilia. Haemophilia 2018;24:548-56.

112. Rodriguez-Merchan EC, Gomez-Cardero P, MartinezLloreda Á, et al. Arthroscopic Debridement for Ankle Haemophilic Arthropathy. Blood Coagul Fibrinolysis 2015;26:279-81.

113. Kaya Bicer E, Kayaokay K, Alsina A, et al. Role of Arthroscopic Deb-ridement of Hemophilic Ankles. Foot Ankle Int 2018;39:1199-204.

114. Rodriguez-Merchan EC. Total Ankle Replacement in Hemophilia. Cardiovasc Hematol Disord Drug Targets 2020;20:88-92.

115. Dauty M, Gross R, Leboeuf F, et al. Comparison of Total Ankle Replace-ment and Ankle Arthrodesis in Patients with Haemophilia Using Gait Analysis: Two Case Reports. BMC Res Notes 2015;8:768.

116. Buda R, Cavallo M, Castagnini F, et al. Treatment of Hemophilic Ankle Arthropathy with One-Step Arthroscopic Bone Marrow-Derived Cells Transplantation. Cartilage 2015;6:150-5.

117. Hassan S, Cannavò A, Gouw SC, et al. Factor VIII Products and Inhibitor Development in Previously 
Treated Patients with Severe or Moderately Severe Hemophilia A: A Systematic Review. J Thromb Haemost 2018;16:1055-68.

118.van den Berg HM. Different Impact of Factor VIII Products on Inhibitor Development? Thromb J 2016;14:31.

119.Lieuw K. Many Factor VIII Products Available in the Treatment of He-mophilia A: An Embarrassment of Riches? J Blood Med 2017;8:67-73.

120. Franchini M, Frattini F, Crestani S, et al. Treatment of Hemophilia B: Focus on Recombinant Factor IX. Biologics 2013;7:33-8.

121. Monahan PE, Liesner R, Sullivan ST, et al. Safety and Efficacy of Inves-tigator-Prescribed BeneFIX Prophylaxis in Children Less than 6 Years of Age with Severe Haemophilia B. Haemophilia 2010;16:460-8.

122. Chowdary P, Dasani H, Jones JA, et al. Recombinant Factor IX (BeneFix) by Adjusted Continuous Infusion: A Study of Stability, Sterility and Clinical Expe-rience. Haemophilia 2001;7:140-5.

123. Windyga J, Solano Trujillo MH, Hafeman AE. BAX326 (RIXUBIS): A Novel Recombinant Factor IX for the Control and Prevention of Bleeding Episodes in Adults and Children with Hemophilia B. Ther Adv Hematol 2014;5:168-80.

124. Driessler F, Miguelino MG, Pierce GF, et al. Evaluation of Recombinant Factor VIII Fc (Eloctate) Activity by Thromboelastometry in a Multicenter Phase 3 Clinical Trial and Correlation with Bleeding Phenotype. Blood Coagul Fibrinolysis 2017;28:540-50.

125. Graf L. Extended Half-Life Factor VIII and Factor IX Preparations. Transfus Med Hemother 2018;45:86-91.

126. Konkle BA, Shapiro AD, Quon DV, et al. BIVV001 Fusion Protein as Factor VIII Replacement Therapy for Hemophilia A. N Engl J Med 2020;383:1018-27.

127. Powell JS, Pasi KJ, Ragni MV, et al. Phase 3 Study of Recombinant Factor IX Fc Fusion Protein in Hemophilia B. N Engl J Med 2013;369:2313-23.

128. Lambert T, Benson G, Dolan G, et al. Practical Aspects of Extended Half-Life Products for the Treatment of Haemophilia. Ther Adv Hematol 2018;9:295-308.

129. Giangrande P, Abdul Karim F, Nemes L, et al. LongTerm Safety and Ef-ficacy of N8-GP in Previously Treated Adults and Adolescents with Hemophilia A: Final Results from Pathfinder2. J Thromb Haemost 2020;18 Suppl 1:5-14.

130. Wynn TT, Gumuscu B. Potential Role of a New PEGylated Recombinant Factor VIII for Hemophilia A. J
Blood Med 2016;7:121-8.

131. Baumann A. PEGylated Biologics in Haemophilia Treatment: Current Understanding of Their Long-Term Safety. Haemophilia 2020;26:e11-3.

132. Fletcher AM, Tellier P, Douville J, et al. Adverse Vacuolation in Multiple Tissues in Cynomolgus Monkeys Following Repeat-Dose Administration of a PEGylated Protein. Toxicol Lett 2019;317:120-9.

133.Pipe SW, Montgomery RR, Pratt KP, et al. Life in the Shadow of a Dom-inant Partner: The FVIII-VWF Association and Its Clinical Implications for Hemo-philia A. Blood 2016;128:2007-16.

134. Seth Chhabra E, Liu T, Kulman J, et al. BIVV001, a New Class of Factor VIII Replacement for Hemophilia A That Is Independent of von Willebrand Factor in Primates and Mice. Blood 2020;135:1484-96.

135. Ducore JM, Miguelino MG, Powell JS. Alprolix (Recombinant Factor IX Fc Fusion Protein): Extended Half-Life Product for the Prophylaxis and Treatment of Hemophilia B. Expert Rev Hematol 2014;7:559-71.

136.Lyseng-Williamson KA. Coagulation Factor IX (Recombinant), Albumin Fusion Protein (Albutrepenonacog Alfa; Idelvion®): A Review of Its Use in Hae-mophilia B. Drugs 2017;77:97-106.

137.Ezban M, Hermit MB, Persson E. FIXing Postinfusion Monitoring: Assay Experiences with N9-GP (Nonacog Beta Pegol; Refixia ${ }^{\circledR}$; Rebinyn $\left.{ }^{\circledR}\right)$. Haemophilia 2019;25:154-61.

138. Sternebring O, Gabel-Jensen C, Jacobsen H, et al. SteadyState Plasma Concentrations of Polyethylene Glycol (PEG) Are Reached in Children and Adults During Once-Weekly Prophylactic Treatment with Nonacog Beta Pegol (N9GP). BioDrugs 2019;33:673-81.

139.Tjønnfjord GE, Holme PA. Factor Eight Inhibitor Bypass Activity (FEIBA) in the Management of Bleeds in Hemophilia Patients with High-Titer Inhibitors. Vasc Health Risk Manag 2007;3:527-31.

140. Mayer SA, Brun NC, Begtrup K, et al. Recombinant Activated Factor VII Intracerebral Hemorrhage Trial Investigators Recombinant Activated Factor VII for Acute Intracerebral Hemorrhage. N Engl J Med 2005;352:777-85.

141.Levy-Mendelovich S, Levy T, Budnik I, et al. Low Concentrations of Re-combinant Factor VIIa May Improve the Impaired Thrombin Generation of Glanzmann Thrombasthenia Patients. Thromb Haemost 2019;119:117-27.

142.Leksa NC, Aleman MM, Goodman AG, et al. Intrinsic Differences between FVIIIa Mimetic Bispecific Antibodies 
and FVIII Prevent Assignment of FVIII-Equivalence. J

Thromb Haemost 2019;17:1044-52.

143. Rodriguez-Merchan EC, Valentino LA. Emicizumab: Review of the Lit-erature and Critical Appraisal. Haemophilia 2019;25:11-20.

144. Franchini M, Marano G, Pati I, et al. Emicizumab for the Treatment of Haemophilia A: A Narrative Review. Blood Transfus 2019;17:223-8.

145. Mahlangu J, Oldenburg J, Paz-Priel I, et al. Emicizumab Prophylaxis in Patients Who Have Hemophilia A without Inhibitors. N Engl J Med 2018;379:811-22.

146. Pipe SW, Shima M, Lehle M, Set al. Efficacy, Safety, and Pharmacoki-netics of Emicizumab Prophylaxis given Every 4 Weeks in People with Haemophilia A (HAVEN 4): A Multicentre, Open-Label, Non-Randomised Phase 3 Study. Lancet Haematol 2019;6:e295-305.

147.Callaghan MU, Negrier C, Paz-Priel I, et al. Long-term outcomes with emicizumab prophylaxis for hemophilia A with or without FVIII inhibitors from the HAVEN 1-4 studies. Blood 2021;137:2231-42.

148. Shima M, Nogami K, Nagami S, et al. A Multicentre, Open-Label Study of Emicizumab given Every 2 or 4 Weeks in Children with Severe Haemophilia A without Inhibitors. Haemophilia 2019;25:979-87.

149. Oldenburg J, Mahlangu JN, Bujan W, et al. The Effect of Emicizumab Prophylaxis on Health-Related Outcomes in Persons with Haemophilia A with In-hibitors: HAVEN 1 Study. Haemophilia 2019;25:33-44.

150. Wheeler AP, Gailani D. The Intrinsic Pathway of Coagulation as a Target for Antithrombotic Therapy. Hematol Oncol Clin North Am 2016;30:1099-114.

151.Agrawal N, Dasaradhi PVN, Mohmmed A, et al. RNA Interference: Biol-ogy, Mechanism, and Applications. Microbiol Mol Biol Rev 2003;67:657-85.

152.Pasi KJ, Rangarajan S, Georgiev P, et al. Targeting of Antithrombin in Hemophilia A or B with RNAi Therapy. N Engl J Med 2017;377:819-28.

153. Machin N, Ragni MV. An Investigational RNAi Therapeutic Targeting Antithrombin for the Treatment of Hemophilia A and B. J Blood Med 2018;9:135-140.

154. Polderdijk SGI, Huntington JA. Identification of Serpins Specific for Ac-tivated Protein C Using a Lysate-Based Screening Assay. Sci Rep 2018;8:8793.

155. Polderdijk SGI, Adams TE, Ivanciu L, et al. Design and Characterization of an APC-Specific Serpin for the Treatment of Hemophilia. Blood 2017;129:105-113.

156. Schmaier AH. Serpin Targets in Hemostasis/Kinin Formation. Blood 2019;134:1566-8.
157. Chowdary P. Inhibition of Tissue Factor Pathway Inhibitor (TFPI) as a Treatment for Haemophilia: Rationale with Focus on Concizumab. Drugs 2018;78:881-90.

158. Doshi BS, Arruda VR. Gene Therapy for Hemophilia: What Does the Fu-ture Hold? Ther Adv Hematol 2018;9:273-93.

159. Murphy SL, High KA. Gene Therapy for Haemophilia. Br J Haematol 2008;140:479-87.

160. Perrin GQ, Herzog RW, Markusic DM. Update on Clinical Gene Therapy for Hemophilia. Blood 2019;133:407-14.

161. Kuether EL, Schroeder JA, Fahs SA, et al. LentivirusMediated Platelet Gene Therapy of Murine Hemophilia A with Pre-Existing Anti-Factor VIII Immunity. J Thromb Haemost 2012;10:1570-80.

162. Naso MF, Tomkowicz B, Perry WL, et al. AdenoAssociated Virus (AAV) as a Vector for Gene Therapy. BioDrugs 2017;31:317-34.

163. Rosen S, Tiefenbacher S, Robinson M, et al. Activity of Transgene-Produced B-Domain-Deleted Factor VIII in Human Plasma Following AAV5 Gene Therapy. Blood 2020;136:2524-34.

164. Maimela NR, Liu S, Zhang Y. Fates of CD8+ T Cells in Tumor Microen-vironment. Comput Struct Biotechnol J 2018;17:1-13.

165.Zhang L, Handyside B, Murphy R, et al. Prednisolone Does Not Regulate Factor VIII Expression in Mice Receiving AAV5-HFVIII-SQ: Valoctocogene Roxaparvovec. Mol Ther Methods Clin Dev 2019;17:13-20.

166. Kazuki Y, Oshimura M. Human Artificial Chromosomes for Gene Delivery and the Development of Animal Models. Mol Ther 2011;19:1591-601.

167. Nakano M, Cardinale S, Noskov VN, et al. Inactivation of a Human Ki-netochore by Specific Targeting of Chromatin Modifiers. Dev Cell 2008;14:507-22.

168. Ponomartsev SV, Sinenko SA, Skvortsova EV, et al. Human AlphoidtetO Artificial Chromosome as a Gene Therapy Vector for the Developing Hemophilia A Model in Mice. Cells 2020;9:879.

169. Valentino LA. Considerations in Individualizing Prophylaxis in Patients with Haemophilia A. Haemophilia 2014;20:607-15.

170.Kempton CL, Escobar MA, Roberts HR. Hemophilia Care in the 21st Century. Clin Adv Hematol Oncol 2004;2:733-40.

171. Young G, Tachdjian R, Baumann K, et al. Comprehensive Management of Chronic Pain in Haemophilia. Haemophilia 2014;20:e113-20. 
172. Witkop M, Lambing A, Divine G, et al. A National Study of Pain in the Bleeding Disorders Community: A Description of Haemophilia Pain. Haemophilia 2012;18:e115-9.

173. Kalnins W, Schelle G, Jost K, et al. Pain Therapy in Haemophilia in Ger-many. Patient Survey (BESTH Study). Hamostaseologie 2015;35:167-73.

174. Shapiro AD, Mahlangu JN, Perry D, et al. Treatment of Bleeding Episodes with Recombinant Factor VIII Fc Fusion Protein in A-LONG Study Subjects with Severe Haemophilia A. Haemophilia 2017;23:392-9.

175. Rodriguez-Merchan EC. Treatment of Musculo-Skeletal Pain in Haemo-philia. Blood Rev 2018;32:116-21.

176.Jansen NWD, Roosendaal G, Lafeber FPJG. Understanding Haemophilic Arthropathy: An Exploration of Current Open Issues. Br J Haematol 2008;143:632-40.

177. Phillips WJ, Currier BL. Analgesic Pharmacology: I. Neurophysiology. J Am Acad Orthop Surg 2004;12:213-20.

Cite this article as: Hotea I, Brinza M, Blag C, Zimta AA, Dirzu N, Burzo C, Rus I, Apostu D, Benea H, Marian M, Mester A, Pasca S, Iluta S, Teodorescu P, Jitaru C, Zdrenghea M, Bojan A, Torok-Vistai T, Niculescu R, Tarniceriu C, Dima D, Truica C, Serban M, Tomuleasa C, Coriu D. Current therapeutic approaches in the management of hemophilia-a consensus view by the Romanian Society of Hematology. Ann Transl Med 2021;9(13):1091. doi: 10.21037/atm-21-747
178. Phillips WJ, Currier BL. Analgesic Pharmacology: II. Specific Analgesics. J Am Acad Orthop Surg 2004;12:221-33.

179. Cepeda MS, Camargo F, Zea C, et al. Tramadol for Osteoarthritis. Cochrane Database Syst Rev 2006;(3):CD005522.

180.da Costa BR, Nüesch E, Kasteler R, et al. Oral or Transdermal Opioids for Osteoarthritis of the Knee or Hip. Cochrane Database Syst Rev 2014;(9):CD003115.

181.Fransen M, McConnell S, Harmer AR, et al. Exercise for Osteoarthritis of the Knee. Cochrane Database Syst Rev 2015;1:CD004376.

182. Brosseau L, MacLeay L, Robinson V, et al. Intensity of Exercise for the Treatment of Osteoarthritis. Cochrane Database Syst Rev 2003;(2):CD004259.

183. Rutjes AW, Nüesch E, Sterchi R, et al. Therapeutic Ultrasound for Osteo-arthritis of the Knee or Hip. Cochrane Database Syst Rev 2010;(1):CD003132. 